UNA ARQUEOLOGÍA HISTÓRICA DEL CAPITALISMO UMA ARQUEOLOGIA HISTÓRICA DO CAPITALISMO

\title{
A HISTORICAL ARCHAEOLOGY OF CAPITALISM
}

Mark P. Leone

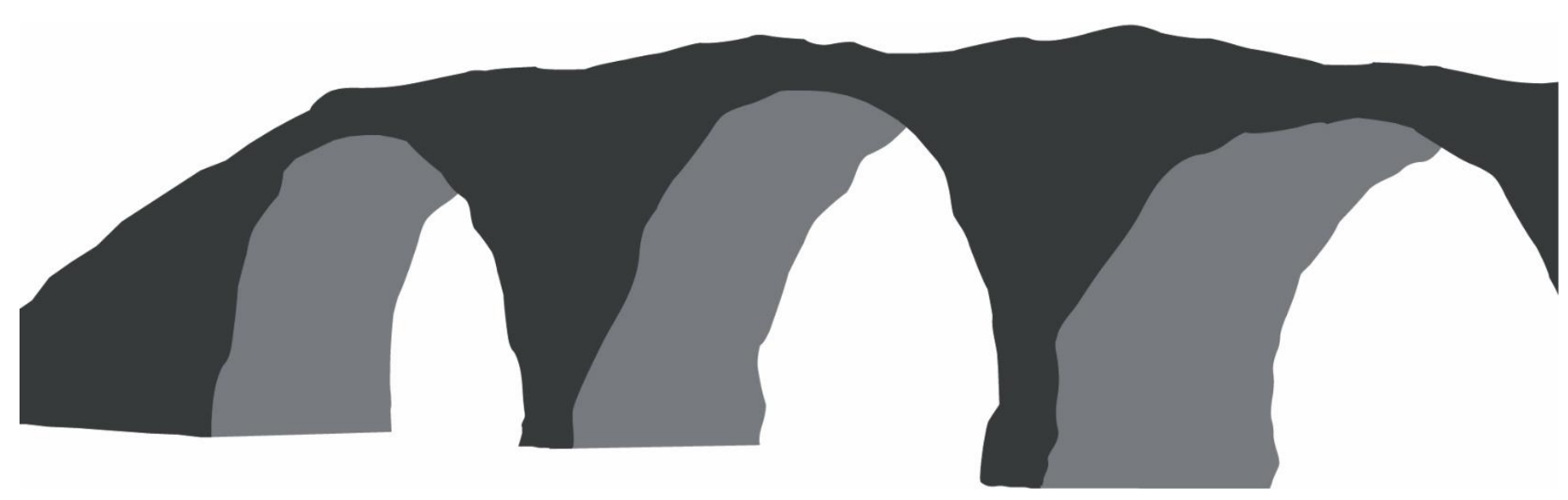




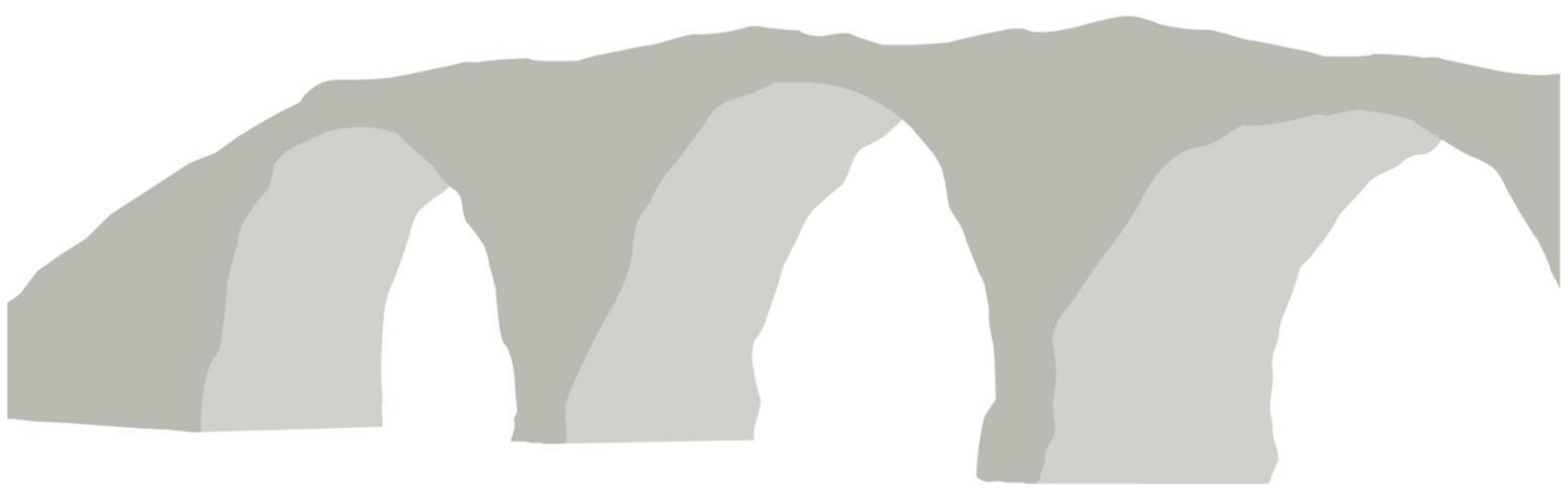

Publicação original:

Leone (1995). A Historical Archaeology of Capitalism. American Anthropologist, 97 (2), p. 251-268.

Reproduced by permission of the American Anthropological Association from American Anthropologist, Volume 97, Issue 2, pp.

251-268, 1995. Not for sale or further reproduction. https: / doi.org/10.1525/aa.1995.97.2.02a00050. 


\title{
UNA ARQUEOLOGÍA HISTÓRICA DEL CAPITALISMO
}

\author{
UMA ARQUEOLOGIA HISTÓRICA DO CAPITALISMO
}

A HISTORICAL ARCHAEOLOGY OF CAPITALISM ${ }^{1}$

\author{
Mark P. Leone ${ }^{2}$
}

\begin{abstract}
RESUMEN
Este artículo se propone discutir el potencial de entender la Arqueología Histórica a la luz de la teoría critica, pensándola como una arqueología del capitalismo. Esta conjunción de ideas permitirá al arqueólogo la construcción de nuevas narrativas criticas sobre las historias oficiales y sus silencios en relación con los grupos subalternos. La neutralidad científica tiene que ser cuestionada para poder pensar la dimensión política de la arqueología y su lugar en la construcción de narrativas. Una arqueología histórica del capitalismo puede desafiar la opresión y contribuir al desarrollo de sociedades más justas.
\end{abstract}

\section{RESUMO}

Este artigo tem como objetivo discutir o potencial de compreensão da Arqueologia Histórica à luz da Teoria Crítica, pensando-a como uma Arqueologia do Capitalismo. Essa conjunção de ideias permitirá ao arqueólogo construir novas narrativas críticas sobre as histórias oficiais e seus silêncios em relação aos grupos subordinados. A neutralidade científica precisa ser questionada para se pensar a dimensão política da arqueologia e seu lugar na construção das narrativas. Uma Arqueologia Histórica do Capitalismo pode desafiar a opressão e contribuir para o desenvolvimento de sociedades mais justas.

\section{ABSTRACT}

This article aims to discuss the potential of understanding Historical Archeology through the light of critical theory, considering it as an archeology of capitalism. This conjunction of ideas will allow the archaeologist to construct new critical narratives about official histories and their silences in relation to subordinate groups. Scientific neutrality has to be questioned in order to think about the political dimension of archeology and its place in the construction of narratives. A historical archeology of capitalism can challenge oppression and contribute to the development of fairer societies.

\footnotetext{
${ }^{1}$ Traducido al español por María Jimena Cruz (postdoctora en el Instituto Multidisciplinario de Historia y Ciencias Humanas (IMHICIHUCONICET). E-mail: jimenacrz@gmail.com. ORCID: https://orcid.org/0000-0001-7133-0873.

${ }^{2}$ University of Maryland, College Park. E-mail: mleone@anth.umd.edu.
} 


\section{CONSIDERANDO EL CONTEXTO POLÍTICO}

Planteo la necesidad de una arqueología histórica más involucrada con las políticas que la sustentan. Defiendo el involucramiento con los factores que han definido la riqueza y el control social en el pasado y continúan haciéndolo en la actualidad. Este compromiso político provee una justificación más coherente para nuestra preocupación con las personas y grupos olvidados, anónimos y desconocidos que son los miembros de las clases explotadas y suprimidas. Estas personas no han sido excluidas de las representaciones oficiales del pasado por error. Más bien, es la política de clases que conduce a la ausencia de inmigrantes, niños, mujeres, esclavos y afroamericanos libres en los modelos de la conducta social que son creados a través de narrativas históricas. Estas políticas no sólo suprimen a los explotados, sino también a sus historias, colocando a la arqueología histórica como el único medio para encontrar su voz.

Sin la consideración explícita de la dimensión política, tanto en un nivel local como en uno mayor, no puede haber un entendimiento adecuado de las bases materiales de la arqueología histórica en nuestra sociedad. Tampoco podremos efectivamente entender la razón fundamental de la arqueología histórica como el estudio de la expansión europea alrededor del mundo. La alternativa es continuar viviendo con nuestra inocencia e ineficiencia política actual.

El llamado a que los arqueólogos históricos consideren la dimensión política y se politicen proviene de dos direcciones. Una tiene su origen fuera de la disciplina y la otra, adentro. Las críticas a la preservación histórica, museos de historia al aire libre, renovación urbana, lugares históricos y turismo constituyen el llamado desde el interior de la disciplina ${ }^{3}$. En números recientes de esta revista ${ }^{4}$, Friedman (1992) y Bruner (1994) resaltaron la centralidad de las preocupaciones políticas cuando un pasado arqueológico es usado para establecer una identidad nacional. Friedman plantea que las personas negocian sus identidades nacionales y locales con una seriedad que evidencia que esas identidades son vitales para la existencia de un grupo. Bruner entiende la discusión de las cuestiones históricas como centrales para la creación de significados y, por lo tanto, centrales en el proceso cultural mismo. Ambos autores son conscientes de que la arqueología tiene un papel importante a desempeñar en los debates acerca del rol político del pasado en la vida de las personas. Cada uno deja en claro que la dimensión política, a su vez, afecta las discusiones del pasado. El contexto inmediato puede ser un debate sobre la economía local y el desarrollo turístico, pero la explicación final para el debate se amplía, dependiendo del autor, para incluir las relaciones de poder entre elites en disputa, la lucha continua por la existencia entre grupos minoritarios, o los procesos por los cuales los humanos generan significados para darle sentido a la vida. Pero a pesar de esos llamados para la concientización política, estos autores no lidian con el hecho de que la arqueología y los arqueólogos no son conscientes de que están involucrados en las relaciones sociales que describen.

Durante los últimos 25 años, los antropólogos culturales han conseguido en gran medida tener la conciencia política que estoy planteando para los arqueólogos históricos. Dell Hymes, en 1970, y más recientemente Clifford, Marcus y Fischer han discutido que el campo de la antropología, al ser históricamente constituido, ha adoptado algunas veces relaciones colonialistas, represivas y de explotación, o ha tratado de

\footnotetext{
${ }^{3}$ Para una crítica sobre la preservación histórica, ver Dorst (1989); para una historia de los museos al aire libre, ver Gable \& Handler (1994); Handler (1988); Wallace (1981, 1984); sobre renovación urbana, ver Williams (1988); Moffett (1989); sobre lugares históricos, ver Lowenthal (1985); sobre turismo ver Anderson (1991); MacCannell (1976).

${ }^{4}$ Nota de la Traductora (N. de la T.): American Anthropologist.
} 
evitar lo político por completo 5 . Hoy en día, los antropólogos se unieron con investigadores de otros campos, como los estudios culturales, para tratar de entender cómo la cultura americana y el capitalismo han dado forma a sus disciplinas.

Los antropólogos culturales, incluyendo Eco, Grossberg, During, Foley, Newman, Varenne, Deming, Passerini, Messick y Connerton han criticado el método etnográfico y defendido lecturas hermenéuticas de fuentes históricas ${ }^{6}$. Ellos prestan mucha atención a la historia local y lo político para discutir los problemas causados por los límites de las disciplinas. A diferencia de varios científicos renombrados, buscan situar su trabajo en ambientes contemporáneos. Muchos de estos escritores usan técnicas deconstructivas derivadas de Derrida (1978) para revelar el rol del presente, aun cuando ese papel está siendo suprimido. Ellos elucidan el rol del capitalismo en la construcción y aprisionamiento de la antropología. Otros, como Foley y Rappaport, se involucraron personalmente y en sus trabajos en las políticas locales ${ }^{7}$. Como arqueólogos históricos, estamos rodeados tanto de invocaciones a entender el carácter político de nuestra investigación como a explicitar la acción política, sin embargo, ninguna de esas llamadas está dirigida específicamente a nosotros.

La segunda llamada hacia la consciencia política proviene de la arqueología misma. Las voces más consistentes surgen de los prehistoriadores británicos, incluyendo Shanks y Tilley, Daniel Miller, Barrett y Hodder y sus estudiantes, que invocan el trabajo de Adorno, Benjamín, Gramsci y Habermas ${ }^{8}$. Por su desarrollo intelectual profundo, el conocimiento de tradiciones político-filosóficas europeas y la cantidad de publicaciones, estos autores tienen pocos paralelos en los Estados Unidos (McIntosh et al., 1989). Los arqueólogos americanos mostraron una tendencia a ignorar estos trabajos y, si eran usados, era solamente en estudios "contextuales" políticamente sanitizados. La llamada dentro de la arqueología internacional para autoevaluarse en términos de poder ha recibido pocas respuestas en los Estados Unidos.

Sin embargo, hay arqueólogos americanos, incluidos Robert Paynter, Randall McGuire, Alison Wylie, Russell Handsman, Thomas Patterson, Parker Potter, Joan Gero, Charles Orser, Janet Spector, Paul Shackel, Barbara Little y yo mismo que hemos escrito acerca del papel formativo que la política local juega en la interpretación arqueológica ${ }^{9}$. El trabajo de los colegas británicos y sus colaboradores ha influenciado claramente nuestros propios esfuerzos. El giro postmoderno en la antropología cultural, inspirado por el trabajo de Schneider y Geertz a mediados de 1970, también ha sido importante para nosotros (Barnett \& Silverman, 1979).

Antecedentes a nuestros propios esfuerzos pueden ser encontrados en el trabajo de Robert Schuyler y Stanley South, quienes propusieron de forma independiente que la arqueología histórica debe preocuparse en estudiar científicamente el colonialismo europeo. Schuyler plantea su posición en palabras claras:

la arqueología de los sitios históricos puede ofrecer una contribución importante a la antropología moderna al estudiar los procesos de expansión europea, explotación y colonización, así como también

\footnotetext{
${ }^{5}$ Ver Hymes (1972); Clifford (1988); Clifford \& Marcus (1986); Marcus \& Fischer (1986); y Marcus (1989).

${ }^{6}$ Ver Eco (1986 [1967]); Grossberg et al. (1992); During (1993); Foley (1990); Newman (1988); Varenne (1993); Deming (1988); Passerini (1987); Messick (1993); Connerton (1989).

${ }^{7}$ Ver Foley (1990) y Rappaport (1988, 1990, 1994).

${ }^{8}$ Libros importantes y artículos incluyen Shanks \& Tilley (1987a, 1987b); Barrett (1988); Hodder (1982, 1986); Johnson (1993).

${ }^{9}$ Artículos y libros relevantes incluyen Paynter (1983); McGuire (1989, 1992); Wylie (1985, 1989b, 1990, 1991, 1992a); Handsman (1980, 1981); McMullins \& Handsman (1987); Patterson (1986); Potter (1994); Gero et al. (1983); Gero \& Conkey (1991); Orser (1988); Spector (1993); Shackel (1991); Barbara Little (1994); Leone (1978, 1981a, 1981b, 1983).
} 
los de contacto cultural e imperialismo que subyacen en uno de los períodos más dinámicos de la historia mundial" (Schuyler, 1979 [1970], p. 28, 30).

Stanley South fue igualmente claro:

La transformación al próximo nivel involucraría datos que reflejan padrones territoriales indígenas sumado a los padrones territoriales coloniales asociados. Estos padrones serían el resultado de una combinación de datos arqueológicos de Gran Bretaña... con aquellos del sistema mundial colonial inglés, formando así nuevos padrones nacionalistas británicos que reflejan el sistema de explotación global.” (South, 1977, p. 2, 4).

Sin embargo, ninguno de los dos autores pensaría probablemente que una investigación del contexto político de los proyectos arqueológicos contemporáneos sería relevante a las cuestiones de la disciplina misma. Por lo tanto, mientras que el trabajo de Schuyler y South es un antecedente al nuestro, porque provee una definición material de la tarea de la arqueología histórica, debemos admitir que las formas actuales de la teoría materialista postmoderna han ido más lejos que la de ellos. Desafortunadamente, la arqueología histórica no ha respondido a estas llamadas, tampoco se ha volcado al estudio de ninguno de los eventos que ellos sugirieron.

Al considerar esta situación en la que me he visto personalmente involucrado, me parece que un número de factores dificulta que la profesión reconozca las realidades políticas que rodean a la arqueología histórica. Traer estos factores a la discusión contribuye a que entendamos por qué el pensamiento materialista postmoderno no ha entrado en nuestra disciplina. Un factor es la afirmación de una neutralidad científica de comienzos de siglo, heredada por generaciones subsiguientes de arqueólogos. Otro es la ausencia de una teoría general capaz de conectar el pasado y el presente dentro del campo de la arqueología histórica. La teoría evolucionista, que aun provee medianamente el marco intelectual de la arqueología prehistórica americana, nunca se consolidó dentro de la arqueología histórica, tampoco ninguna otra teoría ha ejercitado una dominación comparable dentro de nuestro propio campo. Consecuentemente, carecemos de un marco teórico que legitime los métodos que usamos y las investigaciones que diseñamos.

Finalmente, existe el hecho de que las teorías sociales tempranas tendieron a menospreciar la importancia de la cultura material. La mayoría de los teóricos sociales tempranos, incluidos Tyler, Malinowski, Levi-Strauss y Weber, hicieron poco o ningún uso del mundo material, muchos lo consideraron como un mero derivativo. A pesar de que el carácter de la arqueología que se orienta a las cosas entra en desacuerdo con estas teorías sociales, la mayoría de los arqueólogos aceptaron la naturaleza derivativa de la cultura material que estudiaban. Los arqueólogos utilizaron artefactos simplemente para reconstruir modelos de la vida social pasada de acuerdo con las teorías antropológicas entonces vigentes. Por lo tanto, proporcionaron poca información novedosa; y la mayoría de los teóricos sociales, a su vez, tenían poco uso para las preguntas a pequeña escala de los orígenes o el desarrollo social que manejaban los arqueólogos.

Sin embargo, los teóricos postmodernos han hecho posible la conexión entre la cultura material y el mundo de lo político. Entre los avances importantes se incluyen la idea de Giddens de 1984 de estructuración y la de Foucault de 1979 sobre el ejercicio del poder a través de las tecnologías del yo. Aquí es más útil el argumento de Giddens de que la cultura material, como el lenguaje, forma los significados de sus usuarios $-\mathrm{o}$ vidas- en el uso. De esta forma, el hacer, como el hablar, puede ser planteado como una parte, de hecho una parte indispensable, para crear cultura. Esta idea, encontrada originalmente en Marx, fue dada a conocer tiempo después por Gordon Childe, pero en Giddens tenemos un descendiente intelectual poderoso de estos 
dos. El trabajo de Foucault puede ser usado para especificar aún más el de Giddens. El estudio de Foucault sobre las tecnologías de poder me permitió usar el estudio del poder local para conectar la política con la arqueología. A pesar de que he leído alguno de sus escritos, no conocía el trabajo de Foucault sobre las disciplinas del poder cuando comencé con la Arqueología histórica en Annapolis, Maryland en 1981. Sin embargo, creo que, sin las ideas ofrecidas en Vigilar y Castigar, mi trabajo habría sido mucho menos substancial.

Si la arqueología histórica debe preocuparse por lo político y con la acción política, debe tener un método para conectar a los arqueólogos con los escenarios locales. Los trabajos de George Lukács y Jürgen Habermas ofrecen dos modelos, de alguna forma diferentes, para estudiar el pasado en relación con el presente. Ambos escritores ajustan los fundamentos conocidos para estudiar el pasado y las circunstancias modernas al reconocer el impacto de las relaciones de clase y al plantear la cuestión de la utilidad que puede tener el conocimiento del pasado.

En su famoso "Reificación y consciencia del proletariado", Lukács (1971) plantea que la tarea del historiador es descubrir los orígenes de las tergiversaciones modernas basadas en la clase. Tales ideologías son las racionalizaciones generadas por prácticas como la esclavitud, el sexismo, el racismo y otras formas de explotación. Lukács plantea que los miembros de otras clases, más allá de las de la elite y la burguesía, pueden ver claramente su propia posición presente si se les puede mostrar un pasado en el que su condición era diferente. Tal forma de historia implica perforar las ideologías de enmascaramiento utilizadas para convencer a los grupos marginados de que ellos mismos son responsables de su condición actual o, alternativamente, que su condición es natural, universal, divinamente ordenada, establecida por los Padres Fundadores, o históricamente inevitable. Dado que la ideología se presenta a ella misma como atemporal (Althusser, 1971), un arqueólogo puede perforar las máscaras que subordinan a las personas y a los grupos para alcanzar y describir los tiempos en las que esas condiciones no existían. Tal conocimiento puede llevar a una consciencia más efectiva de las condiciones económicas y políticas actuales. Esto, a su vez, puede llevar a la formación de alianzas entre los grupos que han sido tratados similarmente pero que han aprendido a verse a sí mismos como, por ejemplo, étnicamente diferentes; esto a su vez, puede llevar a una acción política más efectiva. En todos sus trabajos, Lukács estaba comprometido con una crítica que consideraba al capitalismo como el productor de una sociedad que debía ser desafiada y reemplazada.

Sin embargo, es extremamente difícil lograr consciencia de clase y casi imposible sustentarla. Ciertamente, ha sido difícil lograr un conocimiento general suficiente sobre las condiciones de explotación comunes para sostener alianzas entre grupos de trabajadores en los Estados Unidos. En un intento para lidiar con este problema, que ha sido conocido por décadas, Jürgen Habermas propuso la noción de una situación de discurso ideal.

Habermas propone que el ambiente político más deseable es aquel en el que existe un diálogo entre iguales ${ }^{10}$. Su modelo comienza con el discurso entre partes desiguales y propone formas de lograr una mayor igualdad de relaciones entre ellos. El objetivo es "nivelar el campo de juego". Para Habermas, el discurso entre iguales tiene cuatro características: inteligibilidad, honestidad, legitimidad y credibilidad. "Inteligibilidad”, para Habermas significa que el discurso es conducido en términos comprensibles para todas las partes. "Honestidad" significa que todas las partes son sinceras en sus intenciones. "Legitimidad" significa que la negociación entre

\footnotetext{
${ }^{10}$ Ver Habermas $(1970,1979,1984)$ y Kemp (1988).
} 
todas las partes determina qué tópicos y términos del discurso serán permitidos y prohibidos. "Credibilidad" involucra un deseo por parte de todos los participantes de colocar sus interpretaciones propuestas a la crítica.

Cuando las partes están compitiendo por materiales arqueológicos, dentro y fuera del campo, dos objetivos son importantes. Primero, todas las partes deben comprometerse a la preservación y mejora de la cultura que está siendo estudiada. Como el deconstruccionismo ha demostrado (Shanks \& Tilley, 1987a, p. 68-99), los métodos científicos de estudio tienden a degradar la cultura de los otros, así como a los otros mismos, al medirlos, compararlos, objetificarlos y desnaturalizarlos. Los arqueólogos, sin embargo, también son capaces de proporcionar a los grupos marginados una visión del pasado definida como valiosa por esos mismos grupos. Los números del primer Congreso de Arqueología Mundial contienen varios ejemplos de arqueología hecha en conjunto con aquellos que generalmente son pensados como el "otro"11. Un punto de vista alternativo puede ser alcanzado de esta forma. La arqueología misma puede, entonces, conseguir ese primer objetivo.

El segundo objetivo es mejorar la democracia al ecualizar un diálogo que ha sido dominado de forma prolongada por el discurso experto de la ciencia. Esto puede ser logrado al quebrar la posición dominante que los miembros de las jerarquías científicas, generalmente, se conceden a sí mismos en diálogo con otros.

A pesar de que casi todos, casi todos los días, utilizan las estrategias de negociación Habermasianas en el discurso ordinario, estas estrategias generalmente no se consideran parte del trabajo arqueológico. Sin embargo, los arqueólogos históricos pueden considerar útil tener en cuenta tales negociaciones explícitamente. Las clases, en una sociedad capitalista, generalmente son mantenidas en sus lugares por ideologías que sostienen que el lugar social es el resultado de factores ineluctables (como diferencias genéticas o históricas). Sin embargo, cada uno de estos grupos también tiene una historia y una cultura material, que a veces funcionan para preservar la unicidad, como en la celebración del arte popular, pero también pueden simbolizar o incluso actualizar la subordinación del grupo, como con algunos objetos de consumo masivo. En un diálogo con un estudioso de la sociedad capitalista, las preguntas de cada grupo sobre su pasado, según lo formulado por sus miembros, podrían proponer temas útiles para los investigadores de la cultura material, incluidos los arqueólogos históricos.

De esta forma, Lukács y Habermas producen dos lógicas diferentes para el trabajo de entender e interpretar el pasado. Lukács hizo un llamado a los historiadores para que redirijan su trabajo y hablen con aquellos apresados dentro de la ideología. Él hizo del historiador un aliado esencial para el trabajador y dirigió el cambio social para favorecer los intereses de los trabajadores. Habermas, por el otro lado, entiende el trabajo del historiador como resultado de un diálogo entre historiadores (quienes explícitamente reconocen tanto su experiencia y sus intereses preexistentes) y las personas que viven en una cultura diferente pero explícitamente valorizada. Habermas ubica el valor del trabajo histórico, en un sistema capitalista, en las diferencias entre sus clases, específicamente entre aquellos que son conocedores culturales y aquellos que están fuera del sistema (o intentan estarlo). Las prácticas de estos grupos, al resistir al capitalismo, pueden constituir una crítica implícita del mismo que, si se describe y conoce, podría alivianar los efectos del capitalismo. Este es el trabajo del científico social, incluido, por extensión, el del arqueólogo histórico.

Por supuesto, la posición de Habermas puede ser altamente problemática: la habilidad del capitalismo en la sociedad americana de absorber la crítica y neutralizar maneras alternativas de vivir es bien conocido por

\footnotetext{
${ }^{11}$ Ver, por ejemplo, Layton (1988, 1989); Shennan (1989); y Gathercole \& Lowenthal (1990).
} 
muchos. Si lo alternativo no es destruido, puede ser trivializado, romantizado y diluido, y así, ser absorbido en lo establecido; raramente se utiliza productivamente el conocimiento de formas alternativas de vida para la reforma.

Sin embargo, cualquier argumento de este tipo depende del deseo de las personas de entender a la historia como una secuencia de eventos potencialmente controlable y no como un "destino" incontrolable. Estas serían las personas que creen que la historia puede proporcionar un conocimiento útil, que están convencidas que el pasado puede ser algo bueno y que creen que tal conocimiento se puede obtener en colaboración con otros cuyos motivos generalmente no se han emparejado con los propios. Hemos probado las propuestas de Lukács y Habermas en Annapolis a medida que continuamos nuestra lucha para unir nuestros propios propósitos arqueológicos y las posibilidades políticas.

\section{DECONSTRUCCIÓN DE LA HISTORIA LOCAL}

Me gustaría ofrecer un ejemplo que tiene algunas implicancias generales para una arqueología histórica políticamente consciente. Como este ejemplo demostrará, mis colegas y yo no hemos evitado las dificultades de una arqueología política, por el contrario, hemos vivido con ellas. Hemos probado los enfoques Lukácsianos en la arqueología histórica, nuestra intención era la de elevar el nivel de la consciencia entre los turistas y residentes de Annapolis. En esto, hemos fallado. Sin embargo, también comenzamos lo que desde entonces se ha convertido en un diálogo a largo plazo bastante exitoso con personas de las diversas comunidades Afroamericanas de Annapolis.

Mi relato comienza con las observaciones que llevaron a la deconstrucción de la historia local, en las cuales conceptos Althusserianos fueron usados para revelar las ideologías operando en las representaciones históricas. Fue asumido que tales representaciones eran creaciones culturales que servían para no desafiar las relaciones sociales en el presente y perpetuarlas en el futuro.

Durante los últimos 18 años, me he comprometido a entender la región de Chesapeake a través de la arqueología histórica. Con tal compromiso, uno hereda un conocimiento rico y substancial sobre el asentamiento europeo en el área ${ }^{12}$. Uno también hereda el esfuerzo, en curso desde que Mount Vernon se convirtió en la primera casa histórica de la nación en la década de 1850, de crear interpretaciones nacionales de la historia de Estados Unidos en la región que contiene la capital de la nación. A lo largo del tiempo, la arqueología histórica y los estudios de cultura material han jugado un papel cada vez más importante en ambas cuestiones. Trabajos arqueológicos básicos y sólidos han sido realizados en el área de Chesapeake por más de 60 años. Las fuertes tradiciones arqueológicas en Jamestown, Colonial Wiliamsbrug y la ciudad histórica de St. Mary han ayudado a definir cronologías, métodos y usos para la arqueología histórica americana ${ }^{13}$. Sin embargo, surge un problema cuando se observa este trabajo de cerca. La arqueología y los museos que la emplean supuestamente tratan sobre los orígenes estadounidenses, pero en realidad ambos están separados de prácticamente todos los aspectos de la vida estadounidense contemporánea. La cerámica y otros artefactos recolectados y exhibidos en los museos no están conectados con temas involucrando patriotismo, tolerancia,

\footnotetext{
${ }^{12}$ Trabajos importantes incluyen Carr \& Jordan (1974); Carr \& Walsh (1980, 1988); Carr et al. (1988); Tate \& Ammerman (1979); y Carson et al. (1993).

${ }^{13}$ Sobre Jamestown, ver Cotter (1958), Cotter \& Hudson (1957); sobre Colonial Williamsburg, ver Noel Hume (1963, 1983); sobre la ciudad histórica de St. Mary's City, ver Miller (1986, 1988), Stone (1974).
} 
condiciones urbanas, condiciones económicas, clase, regiones de la ciudad, pobreza, esclavitud o emancipación. Tampoco explican por qué la arqueología de este patrimonio precisa ser protegida.

Cuando comencé mi trabajo, me sorprendí de que no hubiera una tradición comparativa en arqueología histórica. No eran formuladas preguntas acerca de la fundación y desarrollo de las ciudades, instituciones, clases, granjas, paisajes, dinero, mercados y comercio; Savannah, Charleston, Alexandria, Filadelfia, Nueva York, Boston y Annapolis no eran comparadas en ningún nivel. Las preguntas evolucionistas de la Nueva Arqueología, relativas a las poblaciones, agricultura y ciudades no eran preguntadas en el área del Chesapeake del siglo 17 y 18. Y, aun así, era asumido por historiadores, arqueólogos históricos y el público que eran nuestros orígenes nacionales los que estaban exhibidos en los museos, conectados por un maravilloso relato del desarrollo nacional a los Estados Unidos de hoy. Parece que no hay nada accidental sobre lo que sucedió aquí; era inevitable que la vida en la época colonial se convirtiera en la vida que todos llevamos en la actualidad. Sin embargo, la historia que estos museos presentan es irrelevante para nuestras vidas.

Mi deconstrucción se centra en esta ideología: un "entonces” específico colonial nos llevó a todos “nosotros” a este ahora. Si es así, ninguna pregunta sobre la evolución de la economía política americana necesita ser hecha. Se vuelve el trabajo de los académicos proveer los detalles verificadores y no hacer preguntas sobre la ideología misma. Sin embargo, si una representación local pero nacionalmente dirigida de la historia de Estados Unidos se somete al tipo de preguntas que los materialistas históricos hacen sobre el capitalismo, el resultado de la historia que se presenta ya no parece inevitable. Una historia alternativa podría empezar con las clases durante la época de su creación. Esta historia alternativa podría vincular grupos privados de derechos y la ideología que los atraviesa; podría provocar que algunos espectadores tengan una mayor conciencia de sus propias posiciones.

El descubrimiento y asentamiento inicial de la región de Chesapeake por los españoles en el siglo 16, la ausencia prácticamente de esclavos en la sociedad inglesa de Chesapeake, la presencia de africanos libres, la naturaleza fluida de la riqueza y la amplia disponibilidad de tierras hasta 1660 o 1680 proveen una mirada a una sociedad con fines de lucro que aún no estaba fijada o estratificada - totalmente diferente a la que se exhibe en Colonial Williamsburg, la versión canónica de la forma en que se fundó América.

Después de aislar la ideología de la "inevitabilidad”, podemos buscar una historia alternativa en los trabajos de los historiadores de Chesapeake, Edmund Morgan y Rhys Isaac. Ellos se preguntan una serie de cuestiones diferentes: ¿Por qué algunas personas son pobres? ¿Cómo es que otros se hacen y se mantienen ricos? ¿Cuál es la relación entre ellos? También preguntan por qué fue necesaria la revolución estadounidense para afianzar estas relaciones desiguales. Finalmente, se preguntan a quién sirve esa historia.

Hace más de una década, Rhys Isaac (1982) argumentó que la nobleza de Virginia, que había estado perdiendo poder constantemente desde la década de 1740, lideró la Revolución Americana para evitar perder aún más su poder. Argumentó que los fundadores del país utilizaron las ideas de libertad para crear una alianza entre los granjeros blancos pobres, los trabajadores de la ciudad y la nobleza, basada en la ilusión de que un lazo profundo, el deseo de la libertad, los unía a todos. Fue esta alianza la que venció a los ingleses.

Anteriormente, en 1975, Edmund Morgan había presentado su propuesta más famosa. En "Esclavitud Americana, Libertad Americana”, planteó que la esclavitud en el siglo 18 era vista como la causante de las mismas consecuencias desafortunadas que la pobreza. En las mentes de los fundadores, tanto la esclavitud como la pobreza produjeron personas que no estaban en condiciones de participar del gobierno. Los esclavos y pobres llevaban vidas impredecibles a causa de la pobreza, lo que los hacía tanto ingobernables como no aptos para 
gobernar. Morgan argumentó, sin embargo, que la pobreza de los trabajadores fue esencial para América en cualquier época; y que la pobreza y los trabajadores han estado vinculados intelectualmente a lo largo del siglo 18. Fue la pobreza de los trabajadores lo que hizo la independencia posible para aquellos que eran ricos. La libertad americana, entonces, dependió de la pobreza endémica, de la cual la esclavitud era una forma extrema. Aquí surge una pregunta académicamente poco popular sobre la clase, enraizada en la historia del área de Chesapeake, rica en esclavitud y pobreza. Los arqueólogos explorando la hipótesis de Morgan podrían hacer preguntas como estas: ¿Cómo fue mantenida la pobreza endémica? ¿Qué evidencia arqueológica de clases y resistencia de clases puede ser encontrada? ¿Qué usos se les dio a los mecanismos de mercado? ¿Cuál era el nivel de subsistencia local? ¿Qué ideologías mantuvieron el sistema de pobreza endémica? ¿Qué éxitos y fracasos tuvieron? ¿En qué cultura material se corporizó todo esto? ¿A quién le interesaría saber sobre esto?

\section{PLANIFICACIÓN URBANA BARROCA Y PANÓPTICA}

Las respuestas a tales preguntas pueden quebrar la ideología que propone un recorrido regular e inevitable de la época colonial a la América de hoy. Trabajar con tales cuestiones coloca a la arqueología realizada actualmente en el área de Chesapeake en línea con las exploraciones que enfatizan las formas en que el poder es creado y distribuido entre los grupos. Una forma sencilla de hacer esto proviene de observar los paisajes y áreas urbanas como esfuerzos tridimensionales de control, y no solo como planos de dos dimensiones para la circulación, comercio y eficiencia.

El trabajo de Henry Miller (1988) sobre la ciudad Histórica de St. Mary demostró que la capital del siglo 17 de Maryland tenía un plan de urbanización barroca, que usaba calles que convergían en un centro para crear vistas entre la casa del gobernador, la iglesia católica, el capitolio y la cárcel. Anteriormente, los investigadores no habían considerado que la ciudad tenía una planificación. Había una asunción ampliamente implícita que la localidad no era ordenada, por lo tanto, nadie buscó evidencia de que la ciudad era planificada. Adicionalmente, historiadores y arqueólogos habían creído que grandes secciones del asentamiento original habían sido erosionadas por la Bahía de Chesapeake; desde que Miller realizó su trabajo, se ha vuelto evidente que la totalidad de la ciudad sobrevive arqueológicamente.

En el caso de Annapolis, es un hecho establecido que hubo una planificación de una ciudad barroca. Mis colegas y yo, sin embargo, adicionamos dos puntos a la literatura sobre planificación barroca ${ }^{14}$. Primero, los planos de las ciudades barrocas eran tentativas explícitas de crear ilusiones diseñadas para realzar centros de poder, usando las leyes de la perspectiva codificada por los teóricos renacentistas italianos Alberti y Salviati (Bacon, 1968). Segundo, aun en los tiempos de los primeros asentamientos, los europeos en el área de Chesapeake estaban dando forma a paisajes, tanto urbanos como rurales, a través de ilusiones que buscaban establecerlos en el poder. Habían leído escritos teóricos europeos sobre el uso de las ilusiones de la perspectiva para lograr realzar el poder, y usaron ese conocimiento desde el comienzo. Por lo tanto, el área alrededor de Washington siempre contuvo ilusiones creadas para establecer el poder de aquellos que la construyeron. Nosotros éramos los únicos que no lo sabíamos.

Uno se puede preguntar si las consecuencias físicas y políticas del urbanismo barroco permanecen intactas en el área de Chesapeake. Las teorías barrocas de poder intentaron establecer jerarquías sociales estratificadas

\footnotetext{
${ }^{14}$ Ver Leone (1984,1987); Leone \& Shackel (1990); y Leone \& Little (1993).
} 
al crear ambientes que proclamaban una ley natural dependiente de una jerarquía natural y divinamente ordenada. Esta es la teoría detrás del orden de la gran mayoría de las plantations del siglo 18. Pero ¿podrían los planes de la nueva república federal Americana ser promovidos por una teoría de poder similar? La respuesta a esta pregunta también resuelve el problema de Chesapeake sobre cómo controlar a una población empobrecida y potencialmente ingobernable. En 1750 en Annapolis, por ejemplo, al menos 25 por ciento de la población consistía en esclavos y 5 por ciento de la población censada poseía, al morir, 85 por ciento de la riqueza ${ }^{15}$. Desde 1720 , la distribución de la riqueza en la sociedad de Chesapeake se había vuelto más y más desigual, y poco cambiaría después de 1775.

La respuesta también permite conectar el trabajo arqueológico e histórico realizado en Chesapeake con la fundación de nuestro régimen democrático, un grupo de eventos que también, en su mayoría, tuvo lugar en el área de Chesapeake. El vínculo que voy a establecer entre la jerarquía barroca y el establecimiento de la república también conecta las políticas de explotación a la arqueología histórica de la subordinación y, especialmente, a los cambios en la urbanización que empezó en la Era Federal (1780-1820). Los historiadores de Chesapeake, Isaac y Morgan plantearon que existieron dos preocupaciones después de la Revolución Americana. Una era mantener la ilusión de unidad entre diferentes clases. La otra era mantener las clases separadas. Algunos trabajarían duro y pacíficamente mientras que otros se mantendrían indiscutidamente en sus nuevas posiciones dominantes.

En ese entonces, en 1780, el estado de Maryland construyó un nuevo domo, o cúpula, en su legislatura pre-revolucionaria en Annapolis, una ciudad que alojó brevemente al Congreso y esperaba ser la nueva capital federal. Una cúpula arquitectónica de ocho lados, de varios pisos que nunca se ha descrito con éxito, la cúpula fue construida para dominar la ciudad. Los intentos de clasificación se han quedado en las descripciones de estilo: la cúpula ha sido llamada, entre otras cosas, Chippendale China, un dispositivo de arquitectura del período Federal incómodamente articulado, la obra maestra de John Shaw (Shaw, un famoso ebanista de Annapolis, había construido el domo) y un intento de mostrar que el estado ahora dominaba la iglesia Episcopal (Anglicana) cercana. En cada uno de los otros lados de este domo-torre, hay cuatro tipos de ventanas en diferentes niveles. Las ventanas miran hacia fuera, abajo y a lo largo de las ocho calles que convergían en un centro y caminos que se acercan al capitolio. Mi interpretación es que la torre es, en efecto, el centro de un panóptico construido a gran escala (Ver Figuras 1 y 2).

El panóptico de Jeremy Bentham, más famoso como modelo de prisión, fue un edificio abovedado con varios lados en el que todos los presos eran visibles desde una posición central, desde la cual todo podía ser observado, pero que ningún interno podía ver a ningún otro. Foucault (1979), a quien le debo mucho de este argumento, muestra que el interno del panóptico siempre se imaginaba a sí mismo siendo visto, lo que inculcaba una auto-observación auto-consciente. Dentro de esta auto-observación panóptica, creo que está la noción Renacentista históricamente anterior que una persona que se define como un individuo es también visible, porque él o ella vale la pena por sí misma. El estado barroco no se enfocó en la multitud, sino en los ojos de la persona que se veía a sí misma como un individuo, y utilizó las reglas de la perspectiva para llamar la atención de esos ojos, persona por persona, hacia el estado. La planificación barroca requiere que ambos extremos de la jerarquía se vean a sí mismos como dignos de atención y la noción del individuo (Rowe, 1966), particularmente en los niveles medios y bajos de la sociedad, lo permitió.

\footnotetext{
${ }^{15}$ Ver Russo (s.d.); ver también Fields (1985); Ives (1979); y Leone \& Shackel (1987).
} 


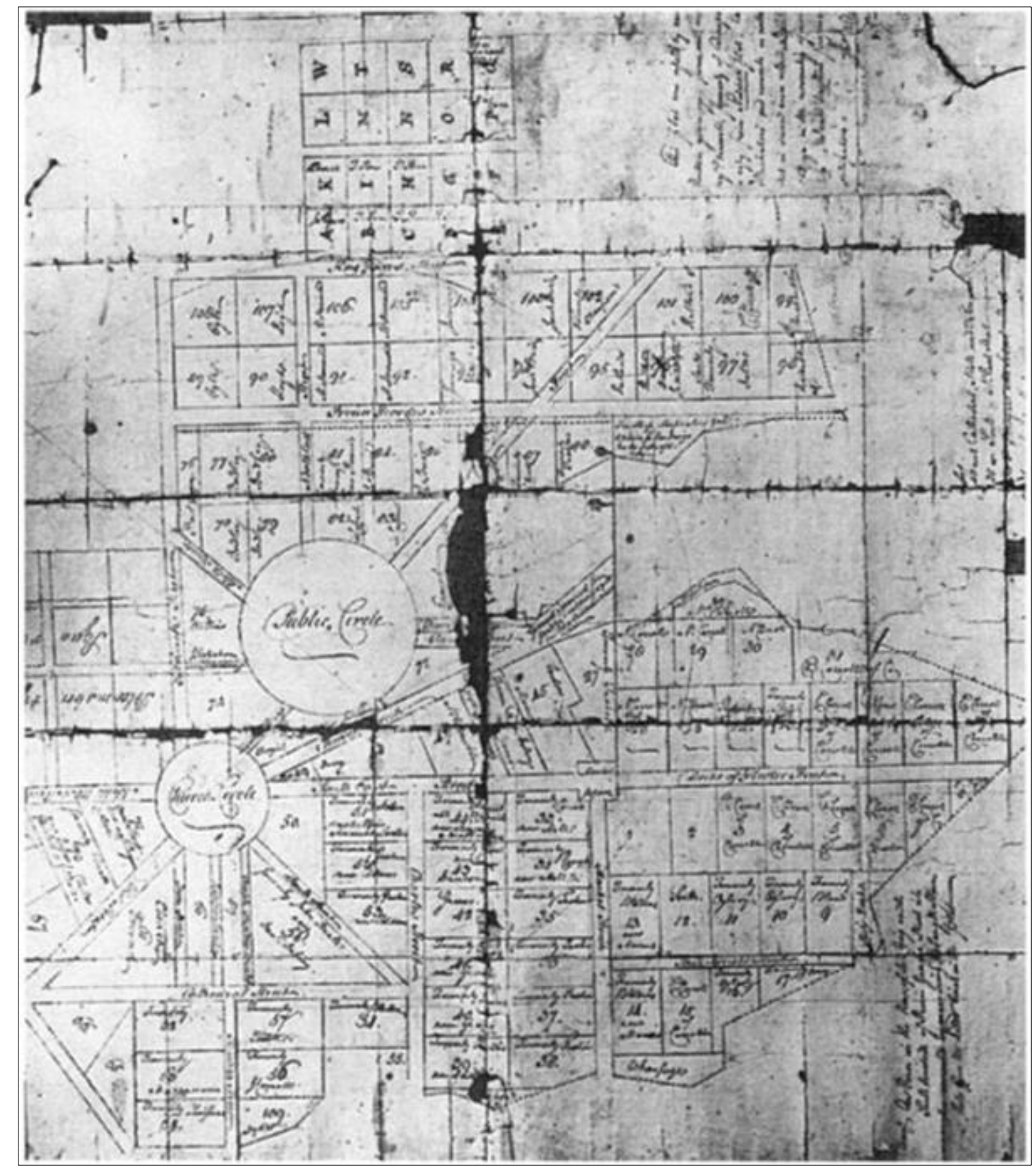

Figura 1. El estudio de Stoddert de Annapolis, 1718, rehecho por Callahan en 1743. La legislatura está localizada en la cima de una colina en el borde inferior izquierdo de un gran círculo. Cortesía del Archivo del Estado de Maryland, COLECCIONES ESPECIALES (Colección de Mapas del Archivo del Estado de Maryland) [MSA SC 1427-1-501].

El panóptico de Jeremy Bentham, más famoso como modelo de prisión, fue un edificio abovedado con varios lados en el que todos los presos eran visibles desde una posición central, desde la cual todo podía ser observado, pero que ningún interno podía ver a ningún otro. Foucault (1979), a quien le debo mucho de este argumento, muestra que el interno del panóptico siempre se imaginaba a sí mismo siendo visto, lo que inculcaba una auto-observación auto-consciente. Dentro de esta auto-observación panóptica, creo que está la noción Renacentista históricamente anterior que una persona que se define como un individuo es también visible, porque él o ella vale la pena por sí misma. El estado barroco no se enfocó en la multitud, sino en los ojos de la persona que se veía a sí misma como un individuo, y utilizó las reglas de la perspectiva para llamar la 
atención de esos ojos, persona por persona, hacia el estado. La planificación barroca requiere que ambos extremos de la jerarquía se vean a sí mismos como dignos de atención y la noción del individuo (Rowe, 1966), particularmente en los niveles medios y bajos de la sociedad, lo permitió.

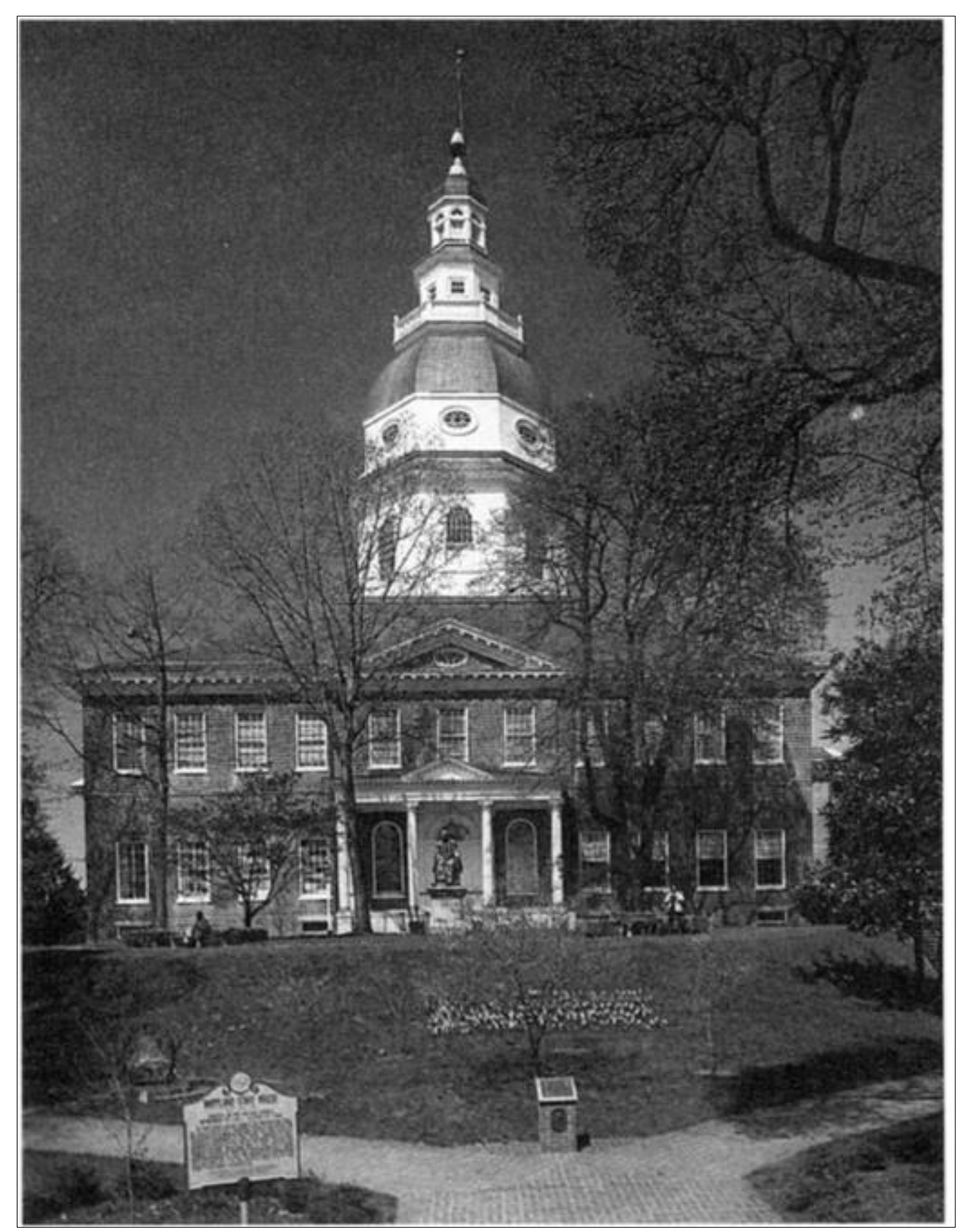

Figura 2. La legislatura de Maryland, Annapolis. La piedra angular fue colocada en 1772, el domo de la torre se completó a finales de 1780. Cortesía de M. E. Warren, fotógrafo, y la Fundación Histórica de Annapolis.

Foucault explicó que en el imaginario del ciudadano del siglo 18 y 19 era una obligación observar y también sentirse observado, monitorear y ser monitoreado, salvaguardar y ser salvaguardado, cuidar y ser cuidado. Solo las personas que se ven a sí mismas como individuos pueden imaginarse a ellos mismos de esta forma. La noción de individuo es, por lo tanto, fundamental tanto para la planificación de edificios barrocos como de los panópticos. 
Me dirijo ahora a la ciudad de Baltimore, en el extremo norte de la Bahía de Chesapeake, que se convirtió en un importante centro de comercio, población y riqueza durante la Era Federal y se promovió como un centro Americano (el Star Spangled Banner ${ }^{16}$ fue creado allí, en todos los sentidos). Baltimore es importante para mí argumento: muestra un vínculo de tres vías entre las tecnologías de poder de Foucault, la definición de democracia dentro del capitalismo y la estructura de clase de la arqueología histórica. En Baltimore, Benjamin LaTrobe y sus colegas arquitectos Federales construyeron una serie de edificios nuevos y exitosos en la Era Federal. Una catedral con cúpula central para los católicos, una iglesia adyacente con cúpula central para los unitarios, una similar para los bautistas, un quirófano con cúpula para la recién establecida escuela de medicina de la Universidad de Maryland, una cárcel destinada a ser panóptica y (como Silas Hurry me señaló) el primer monumento dedicado a George Washington, una torre sobre toda la ciudad. Estos edificios ayudaron a definir las conexiones entre la arqueología del urbanismo y la democracia propuesta para el nuevo país (Ver figuras 3-8).

Estos edificios fueron planificados y construidos como celebraciones de la democracia. Juntos, ellos declaran explícitamente una unidad con la Roma republicana y una distancia de las nociones barrocas de jerarquía. Tenían la intención de destacar a cada ciudadano e invitar a cada uno a una sociedad democrática; también convocaban a cada ciudadano a monitorear al resto. Fueron construidos por republicanos reformistas y victoriosos que votaron, pelearon, hablaron, se impusieron impuestos y se eligieron mutuamente, viviendo estas prácticas en los edificios que construyeron. Dentro de estos edificios, los ciudadanos reconocieron la mirada del líder a quien le dijeron que podían compararse por un voto, una tarifa, una oración secular o cualquier otra muestra racional de aceptación.

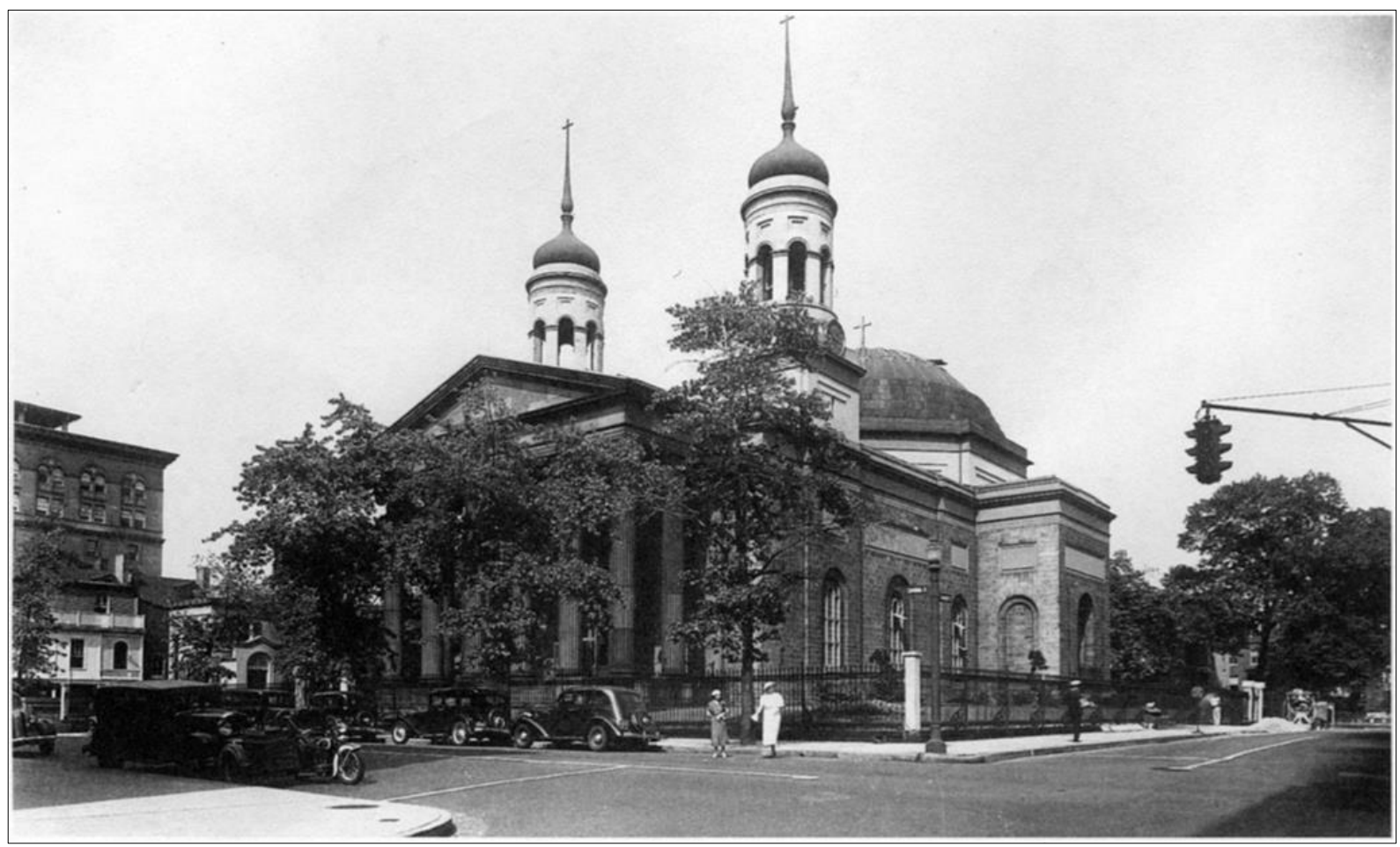

Figura 3. Exterior de la catedral Católica Romana de Benjamin LaTrobe en Baltimore (1808-21). Cortesía de HABS, Biblioteca del Congreso [HABS MD 4-BALT 41-1 MD186].

${ }^{16}$ Nota de la Traductora (N. de la T.): Nombre con el que se conoce el himno nacional norteamericano. 

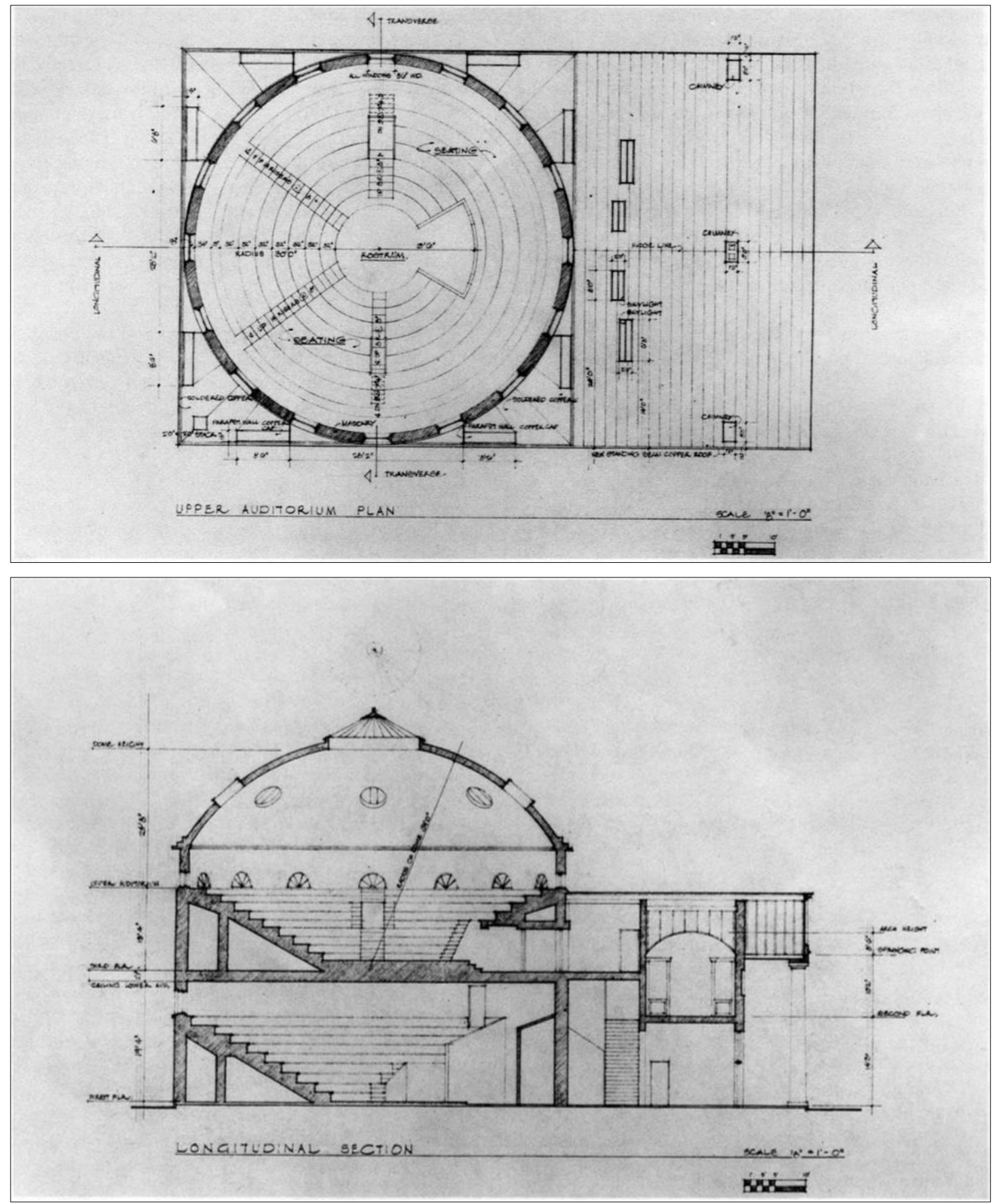

Figuras 4 y 5. Superior: plano del auditorio superior del Davidge Hall, Baltimore, el primer edificio de la Universidad de Maryland. Cortesía de HABS, Biblioteca del Congreso [HABS MD 4-BALT 59B, No 5 of 11]. Inferior: sección longitudinal, Davidge Hall (1812), Universidad de Maryland, Baltimore. Cortesía de HABS, Biblioteca del Congreso [HABS MD 4-MDBALT 59B 304, No 8 of 11$]$.

Como edificios, incorporaron y facilitaron una mirada panóptica. En las filas semicirculares debajo de los domos bajos, los cuartos iluminados por grandes ventanas de vidrio permitieron a las personas verse y oírse unas a otras. Sobre todas ellas, Washington contemplaba sobre el centro poblacional de la ciudad. La columna de Washington, construida alrededor de 1820, era visible en todas partes, como la torre de la legislatura de Maryland. Un gran espacio urbano, lleno de casas y llamado Mt. Vernon Square fue construido rodeándola. La 
columna tenía un cuarto abovedado en su base para reuniones y las personas subían regularmente a la parte superior de la columna hueca.

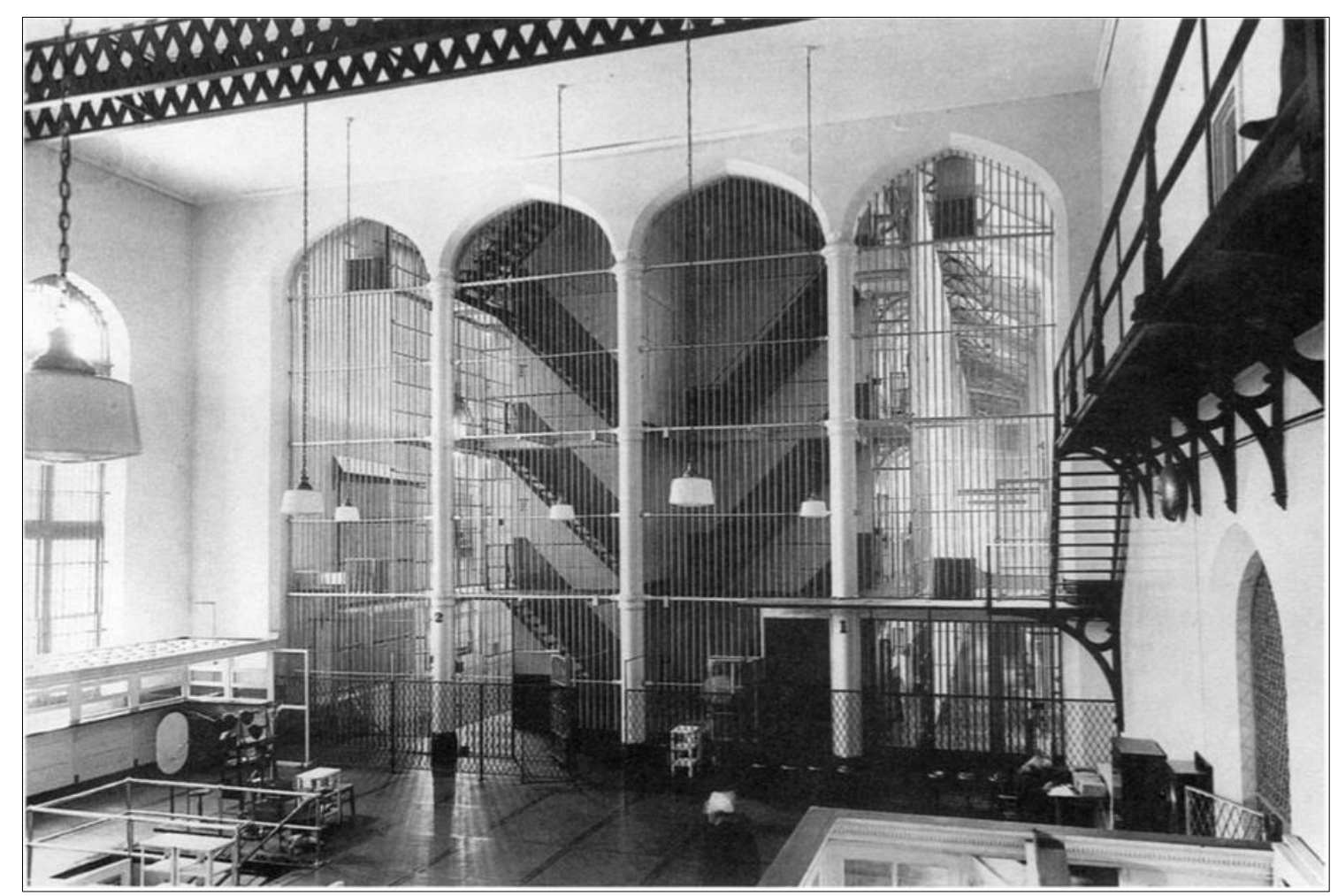

Figura 6. Interior de la Prisión Central de Baltimore (1859) mostrando vistas panópticas modificadas en el bloque de celdas. Cortesía de HABS, Biblioteca del Congreso [HABS MD 4-BALT 112-6 MD 184].

Las personas de Baltimore eran ciudadanos de un estado inestable marcado por el alto consumo de alcohol, baja asistencia a la iglesia y una estructura familiar degradada (Smith 1985; Smithsonian Institution 1985). Vivieron durante las rebeliones que marcaron la primera república. Sin embargo, la cuestión, que es también la de Morgan y la mía, era y es ¿cómo era mantenida la paz? ¿Por qué las personas trabajaban bajo estas múltiples miradas? O, para plantear la pregunta de otra forma ¿Cómo se mantuvieron las razas desiguales, las mujeres más subordinadas y las minorías y clases reproducidas?

Las miradas panópticas existieron dentro de las prisiones, así como en las casas, hospitales, manicomios, iglesias, escuelas, bibliotecas, fuertes y minas, los cuales fueron diseñados para la vigilancia. John Cotter (Cotter et al., 1988) excavó el taller de la prisión de Filadelfia de 1760 y encontró los restos de los talleres de artesanías usados para enseñar a los prisioneros a reformarse al aprender oficios útiles. Él no solo explica los detalles de la manufactura de artesanías sino también la razón por la que los talleres podrían ser encontrados en las prisiones. Era la idea del ciudadano auto-disciplinado, el reproductor productivo de la sociedad que fue el responsable final de los restos de fabricación que encontró Cotter. El servicio de té que Noel Hume encontró en el manicomio de Williamsburg probablemente funcionó como el violín que ahora se exhibe en el mismo edificio. El propósito de estos objetos era introducir la conducta ordenada en las mentes desordenadas. Producían (o se pensaba que producían) un comportamiento estructurado en vidas interrumpidas por su ausencia. Las técnicas o disciplinas asociadas a ellos definían la conducta normal como el resultado de una autodisciplina internalizada, que era aprendida o despertada a través del uso de artefactos materiales en instituciones 
panópticas que ejercitaban la vigilancia sobre aquellos que se creía que exhibían un comportamiento marginal: delincuentes, niños, estudiantes, enfermos mentales, los enfermos y otros.

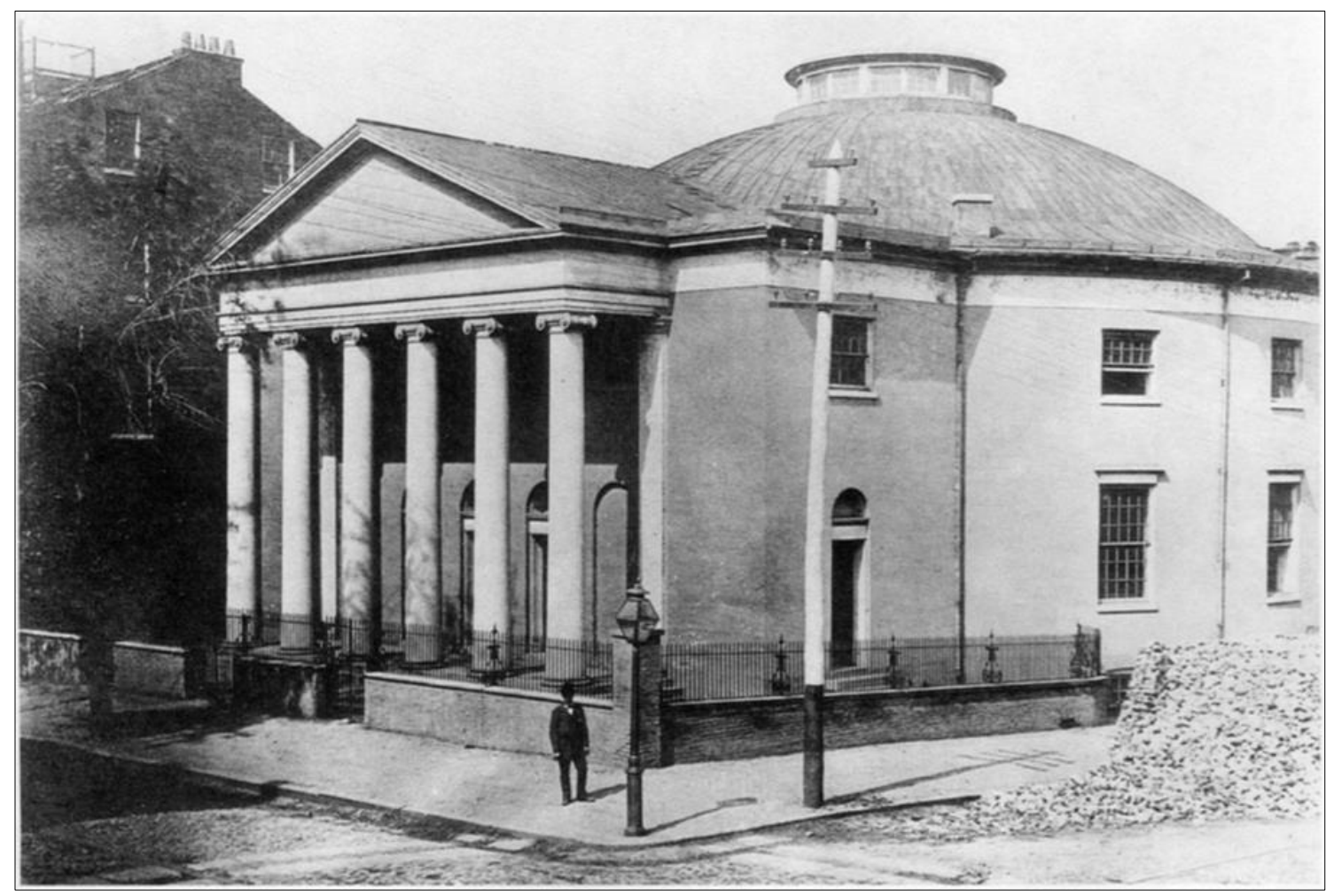

Figura 7. Exterior, Primera Iglesia Bautista de Robert Mill, Baltimore (1818). Cortesía de HABS, Biblioteca del Congreso [HABS MD 4-BALT 37-1 MD75].

Platos, utensilios de cocina, artículos de tocador y otros objetos utilitarios son encontrados en todos los ambientes panópticos, incluidos los hogares. La etiqueta o la disciplina asociada con el comer es como aquella asociada con escribir, medir el tiempo o cualquier otra rutina. Paul Shackel (1993) plantea que a medida que los individuos aprenden reglas para comer, se enseñan, controlan, juzgan y corrigen entre sí al usar las reglas proporcionadas para tales tareas. La auto-disciplina o la tecnología del yo vista en los comportamientos de la mesa, como en la cocina, el servicio y la eliminación de desechos, constituyen formas de auto-mantenimiento. Las personas a las que se les enseña que son individuos, internalizan la mirada que otros les dirigen y aprenden a fijarla sobre sí mismos de manera consistente a medida que usan estos elementos. La observación de sí misma es la marca del ciudadano; si se cumple con éxito, exige trabajo y evita la rebelión. Las prácticas de toilet y los modales en la mesa de las personas que se ven a sí mismos como individuos son algunas de las formas en que una sociedad basada en el trabajo asalariado asegura su propia reproducción.

Cepillos de diente, lápices de plomo, fragmentos de espejos, tenedores, platos para servir salsas específicas, condimentos y fragmentos faunísticos de comidas atestiguan las técnicas de vigilancia de sí mismo que asociamos con el nuevo estado. La hipótesis de Foucault requiere de grandes cantidades de pequeños fragmentos de datos de la arqueología histórica para ser persuasiva. Esta información existe en los objetos, inventarios y edificios que encontramos en la arqueología histórica. A través de la arqueología, tal vez encontremos en ellos tanto la mirada panóptica del estado como la mirada auto-dirigida del ciudadanoindividuo. 
La arqueología histórica puede identificar varias características de los edificios panópticos. No es difícil describirlas. Generalmente tienen plataformas de observación que están aisladas y son aislantes, habitaciones del mismo tamaño, muchas puertas, ventanas exteriores opacas o ventanas que solo dan a espacios confinados y definidos, filas de asientos semicirculares, cuartos circulares y lugares donde cada miembro puede ver y ser visto desde el centro por una persona.

A diferencia de los edificios y paisajes barrocos, que demandan atención a través del uso de vistas y cúpulas, pero no la devuelven, los edificios verdaderamente panópticos facilitan una mirada de doble sentido. Las instituciones panópticas, por lo tanto, comandan al ciudadano emancipado, no al sujeto monárquico; el ciudadano es mandado a observarse a sí mismo precisamente porque él o ella es el lugar teórico de la autoridad del estado. Aunque la escala gigantesca de los edificios en Washington D. C. probablemente disminuya su efectividad, los círculos y el Capitolio, el obelisco del monumento a Washington y la propia mirada de Lincoln desde su memorial crean un paisaje panóptico. Esta no es una ciudad barroca tardía, como generalmente se propone, sino una panóptica. Ciertamente la combinación de la burocracia y medios de comunicación en Washington deja poco lugar a dudas acerca de su efecto vigilante.

Propongo, sin embargo, una continuidad subyacente entre las dos teorías de poder utilizadas en el área de Chesapeake bajo el asentamiento europeo y americano. Ambas produjeron edificios designados para preservar la jerarquía. Yo diría que no hay una diferencia significativa entre la intención política del palacio del gobernador en Williamsburg o los edificios públicos en la ciudad de St. Mary, y los edificios posteriores del período federal en Annapolis. Sabemos que los planificadores de la ciudad barroca crearon calles que convergían en un centro para dirigir la atención del individuo a los centros de poder deseados, pero la obediencia era producida solo en una persona que se identificaba a sí misma como un individuo. Por lo tanto, el acto de ser convocado por el estado reprodujo una ideología individualista. También sabemos que las instituciones barrocas estaban fallando en sustentar jerarquías estables para 1760, de hecho, ellas colapsaron alrededor de 1770 y 1780. Baltimore y Washington no solo son experimentos de construcción, sino que también son reemplazos experimentales para las instituciones barrocas. En dichas ciudades, la nueva democracia federal surgió, la cual hizo de la noción del ciudadano-individuo bajo la mirada panóptica autosustentada su pieza ideológica central.

Por lo tanto, a pesar de que la teoría del poder usada en Williamsburg y Annapolis era barroca, y la usada en Baltimore y Washington era panóptica, varias razones materiales fomentan un argumento de que su propósito era el mismo. Para 1720 la estructura de clases había sido creada en la región de Chesapeake en la cual unas pocas familias centraban la mayor parte de la riqueza, junto con las cortes locales y las oficinas electorales ${ }^{17}$. Este grupo de la alta burguesía había reducido a los blancos más pobres, nativos americanos y afroamericanos a una clase empobrecida, como fue señalado por Terry Eppersen (1990a, 1990b), y se apoyó en el racismo para evitar que la conciencia del estatus económico se convirtiera en una base para la unidad política. La revolución Americana fijó estas clases en su lugar, no alteró su relación. Una arqueología histórica preocupada con el capitalismo, que investiga las raíces de aquellos a los que se les han negado pasados y explica por qué están aquí y ahora en la condición en la que se encuentran, puede usar la organización de las calles de estas ciudades para mostrar cómo el ejercicio del poder en el pasado mantuvo la pobreza y, así, vincular el empobrecimiento del pasado con su continuidad en el presente.

${ }^{17}$ Ver Isaac (1982); Walsh (1983); Russo (s.d.); Leone (1987); y Shackel (1993). 


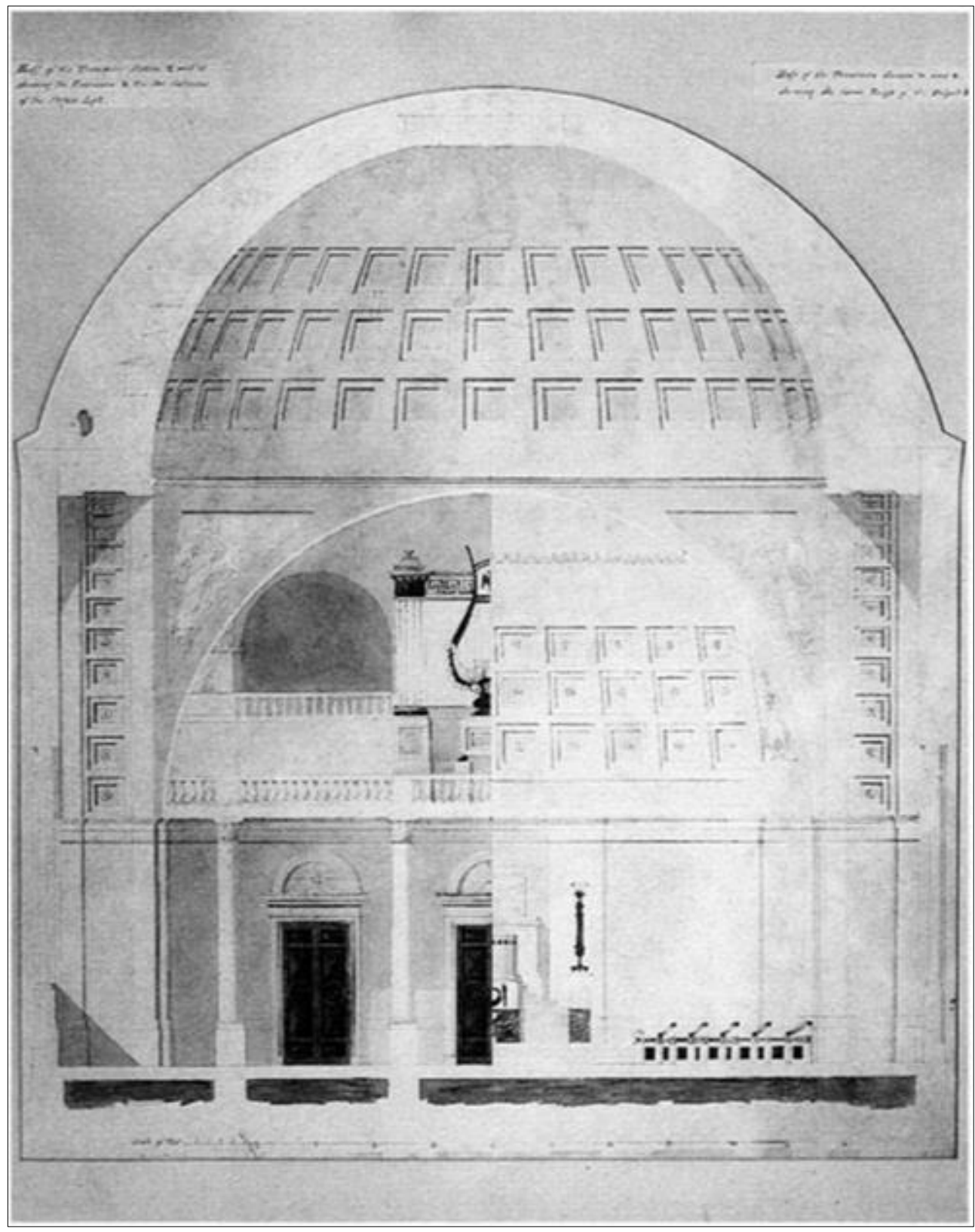

Figura 8. Sección transversal, Primera Iglesia Unitaria de Baltimore de Maxiliam Godefroy (1818). Cortesía de la Primera Iglesia Unitaria de Baltimore y su congregación; fotografía del Museo Peale, Baltimore [MC 2552(7)].

En nuestro trabajo, hemos sido guiados por Lukács, quien definió el trabajo del historiador como el de desafiar al capitalismo. Nuestra preocupación es con el mantenimiento de clases; las teorías de la disciplina y vigilancia de Foucault especifican los puntos en los que el poder es aplicado en la cultura material de la vida cotidiana. En la década de 1980, elaboramos interpretaciones foucaultianas del plan de la ciudad de Annapolis y las reglas del período federal para la alimentación ordenada y la puntualidad (Leone et al., 1987). Arqueólogos entrenados por un productor de teatro especializado en presentar historias de los barrios desarrollaron estas interpretaciones en tours a los sitios arqueológicos de Annapolis. Los recorridos fueron muy populares en toda la ciudad, pero hasta donde sé, no cambiaron la consciencia en lo absoluto (Potter \& Leone, 1992).

La popularidad de estos recorridos, sin embargo, fue útil para nosotros; necesitábamos el apoyo de la ciudad para proteger los sitios arqueológicos que son, después de todo, la propiedad de los propios residentes 
de la ciudad. Pero también nos dimos cuenta de que, en lo que respecta al cambio social, estábamos hablando con la audiencia equivocada. Para que una arqueología histórica del capitalismo sea posible, tendría que haber un diálogo entre aquellos que ven el conocimiento acerca de ellos mismos como una forma de lidiar con su propia opresión o victimización. Esta conclusión, a pesar de no ser tomada de Habermas, está respaldada por su análisis del discurso entre iguales potenciales. Dado que cualquier tipo de arqueología ocurre en un entorno local, no tiene por qué ser difícil identificar a las personas vivas que desean saber más sobre un pasado que ven de alguna manera como propio. Tal compromiso crea preguntas que pueden tener respuestas arqueológicas. Byron Rushing, muy conocido en la arqueología histórica por financiar excavaciones en la African Meeting House en Beacon Hill en Boston (Bower et al., 1984), ha señalado que las personas afro-descendientes quieren saber cómo llegaron a estar aquí ahora. Las personas blancas, por otro lado, no quieren ese conocimiento.

En Annapolis, entonces, comenzamos los diálogos con dos Afroamericanos que estaban a cargo del Museo Banneker Douglass, el Centro para la Historia y Cultura Afroamericana del Estado de Maryland. Nuestros interlocutores tenían tres preguntas para nosotros como arqueólogos ¿Había, de hecho, alguna forma de saber si el material arqueológico estaba asociado a los afroamericanos? ¿Ellos tuvieron participación en el registro? ¿Cómo sería una arqueología histórica afroamericana? Nosotros mismos tuvimos que admitir que no sabíamos las respuestas.

Nuestros colegas Afroamericanos también nos dijeron que estaban cansados de escuchar sobre la esclavitud. Ese tema era bien entendido por las personas negras, quienes lo encontraban degradante y despreciativo. No todas las personas negras eran descendientes de esclavos, después de todo la esclavitud no fue la única condición que las personas afro-descendientes habían conocido ¿Qué pasó con las condiciones en libertad, antes y después de la emancipación? Además, dado que la herencia africana es apreciada entre muchos afroamericanos pero difícil de identificar debido a las condiciones de la diáspora, querían saber si la cultura material africana había dejado restos en el suelo. Estas preguntas, formuladas en 1988, redirigieron el trabajo que estábamos haciendo en varios sitios en Annapolis. Como resultado, recuperamos varios artefactos y patrones de uso únicos, pudimos dar presentaciones públicas de arqueología muy diferentes a los visitantes y patrocinamos la primera historia oral realizada por arqueólogos en Annapolis. También pudimos dar respuestas positivas a las tres preguntas de nuestros interlocutores.

Los vecindarios donde habitaron Afroamericanos desde el siglo 19 hasta la Segunda Guerra Mundial están disponibles arqueológicamente debajo de los lotes de estacionamiento de la ciudad y de los jardines de la Academia Naval de los Estados Unidos ${ }^{18}$. Actualmente, un significativo número de casas, patios y espacios en la ciudad alguna vez contuvieron viviendas afroamericanas, que todavía están intactas arqueológicamente bajo muchas superficies (Logan, 1991). Un tercio de la población de Annapolis es y ha sido Afroamericana, y hay varios barrios donde vivían negros libres tanto antes como después de la Guerra Civil. Sus artefactos muestran que usaron juegos de mesa parecidos a los de cualquier otro, que hicieron un uso selectivo de los mercados dominados por los blancos, que tenían una cocina Afroamericana establecida y que usaron algunos artículos de una forma simbólica diferente a la de los blancos. La evidencia arqueológica muestra una negociación de las clases sobre las identidades de clase a través de diferentes adornos, alimentos silvestres y marcas nacionales producidas en masa (Mullins \& Warner, 1993). La integración y resistencia al mercado ocurrieron

\footnotetext{
${ }^{18}$ Ver Cox \& Seidel (1994); Cox et al. (1994); Bodor et al. (1993); Goodwin et al. (1993); Warner (1992); Warner \& Mullins (1993); y Logan (1991).
} 
simultáneamente. Un pueblo perseguido mantuvo estratégicamente la integridad cultural. Por lo tanto, ahora hay algo de historia de afroamericanos en una ciudad donde su presencia histórica ha sido negada implícitamente durante mucho tiempo.

Hay una amplia oportunidad de conectar edificios, planos de calles y artefactos con el ejercicio de la vigilancia panóptica. Las viviendas en callejones, que son hileras de casas construidas a bajo costo y generalmente alquiladas a Afroamericanos, existen dentro de una docena de manzanas de la ciudad (Hannah Jopling, 1994, comunicación personal). Fueron construidas cuando los interiores de la manzana dejaron de poseer establos y grandes jardines. A partir de fotografías del período, es claro que la cúpula de la legislatura miraba hacia abajo y podría ser vista desde los patios. Gott's Court tenía 25 de estas casas en dos hileras, apoyadas en la parte trasera de la cárcel de la ciudad. De esta forma, los residentes podrían ver directamente dentro del patio de la cárcel, como sus historias orales nos cuentan: "Bueno, solíamos subirnos a la cerca con cajas o sillas o lo que sea para ver a los prisioneros... cuando salían al patio". Nadie recuerda haber visto un ahorcamiento, aunque existe el folclore sobre ahorcamientos anteriores de personas negras: "pero escuche gente gritando" (Jopling, s.d).

En 1994 completamos una gran excavación inmediatamente atrás de la corte del condado, que tenía una torre y una prisión y, al lado, a la Iglesia Episcopal Metodista Africana como vecina. Una hilera de seis casas apretadas detrás fue ocupada por Afroamericanos a principios de siglo. Todas estas personas vivían a pocos metros de instituciones de vigilancia. Algunas eran instituciones paternalistas, sin dudas, pero algunas eran punitivas, y eso es una mezcla panóptica.

La integridad histórica de los afroamericanos se observa a través de la recuperación arqueológica en la casa de Charles Carroll de Carrollton, de un depósito datado en 1790-1810, de cristales de rocas, de monedas perforadas, discos de hueso perforados y otros objetos usados en las actividades de adivinación tradicionales del Oeste Africano (Logan, 1991). A pesar de que esos materiales eran probablemente locales, John Vlach y Gladys Marie Fry (1991, comunicaciones personales), han señalado que esos objetos no solo eran usados en prácticas de África occidental, sino que han sido encontradas en todo el sureste de Estados Unidos en sitios asociados con africanos esclavizados. Narrativas de Africanos anteriormente esclavizados describen un mundo de espíritus habitando la mayor parte de la realidad que, con ayuda especializada, podían ser usados para curar enfermedades, quebrar venganzas, ganar poder, decir la fortuna y asegurar la seguridad personal. Miles de artefactos, incluyendo cuentas azules, tapas de jarras fracturadas, botones, tiestos y huesos blancos, componen depósitos en cientos de sitios del sureste; hablan de una religión (o religiones) poco reconocida por el mundo de las plantations blancas. A través de las religiones y prácticas culturales derivadas de África, los africanos esclavizados podrían eximirse parcialmente del mundo colonizador y del cristianismo blanco (Ferguson, 1992). Si bien estas prácticas eran originalmente de África Occidental, la evidencia estadounidense muestra que fueron tan variadas y duraron tanto que también pueden considerarse productivamente como afroamericanas.

De esta forma, un diálogo ha comenzado entre arqueólogos blancos y Afroamericanos, quienes se han definido a sí mismos, en varias conversaciones, como profesionales, informantes, guardianes, facilitadores, académicos, iguales, estudiantes, extraños, recaudadores de fondos, contribuyentes y -a veces y con malestarsubordinados, ignorantes pero dispuestos a aprender, a que les sermoneen y, ocasionalmente, a que se les rían y les griten. El diálogo ha sido productivo para los blancos, quienes se han comprometido a largo plazo a consultar con los afro-descendientes antes de excavar y escuchar con atención cuando éstos proponen preguntas que puedan tener respuestas en la historia oral y arqueológica. Adicionalmente, la Fundación Histórica de 
Annapolis, uno de los patrocinadores de la Arqueología en Annapolis, ha accedido a recaudar importantes fondos para la restauración de una casa de mediados del siglo 19 construida por una familia afro-descendiente libre, transformándola en una casa museo histórica.

Más de 10,000 personas de las comunidades blancas y afro-descendientes de Annapolis han experimentado exhibiciones de material documental y arqueológico Afroamericano, junto con presentaciones de historia oral. Los Afroamericanos sostienen eficazmente sus reclamos políticos de que tienen territorio para defender, patrimonio para administrar, conocimiento para adquirir sobre los pasados Afroamericanos y muchos estudiantes a los que enseñar o capacitar. Como partes interesadas, presionan por una parte del poder de la comunidad de preservación histórica.

\section{CONSECUENCIAS PARA LA ARQUEOLOGÍA HistÓRICA}

La literatura científica sola no va a sostener a la arqueología histórica en sus estudios de la expansión Europea y la cultura del capitalismo. Varios tipos de conocimientos útiles pueden ser producidos a través de diálogos con aquellos que, de otra forma, serían objeto de la arqueología. Tales diálogos proveen importantes preguntas de investigación, al mismo tiempo que crean un vínculo entre el presente y el pasado e involucran los tipos de conocimiento mutuo que forman parte de la vida política de una comunidad.

Una concepción de la arqueología histórica que asume la importancia de las diferencias de clase presta atención a la dirección de la comunidad e investiga el tipo de explotación endémica del capitalismo que hace inevitable la participación política. Pero también podemos asumir, con Lukács y Habermas, que el entendimiento del capitalismo puede proporcionar formas de cambiarlo. En estos paradigmas, la conciencia es el vehículo del cambio social. En consecuencia, debemos preguntarnos ¿los resultados arqueológicos del diálogo producen conciencia de las condiciones sociales o promueven la participación democrática en un proceso científico previamente aislado? La respuesta, con el tiempo, se está convirtiendo en sí. Como resultado de nuestros propios diálogos, sabemos más acerca de la resistencia a las formas de invadir la vida cotidiana del capitalismo. Sabemos que los primeros Afroamericanos usaron prácticas religiosas africanas y formas distintas de cazar, pescar, comer y realizar banquetes para evitar algunas formas de dominación. Conectamos éstas, utilizando el trabajo de Eugene Genovese (1974) y Barbara Fields (1985), con formas de resistencia afroamericana que se expresaron como ignorancia y olvido fingidos e irresponsabilidad actuada. De esta forma, aun las conductas aparentemente inocuas pueden servir como un antídoto al tipo de explotación que el capitalismo ha creado en el mundo del avance europeo desde 1450.

El diálogo ha producido una descripción comprehensiva de sitios Afroamericanos en la ciudad. Hemos elucidado las diferencias entre cerámicas, vidrios y restos faunísticos en sitios ocupados por grupos Afro americanos y Euro americanos. De igual importancia es la alianza amplia que el diálogo ha creado entre los arqueólogos blancos y sus financiadores, y diferentes grupos de afroamericanos, algunos de los cuales abogan por los pobres. De esta forma, alguna conciencia histórica ha sido creada entre algunas personas, y algunas alianzas han sido formadas. Se ha creado un conocimiento bastante profundo de otros, aunque aún no se ha determinado su uso social y político. Ahora hay varias voces independientes hablando sobre pasados nunca antes conocidos a audiencias plurales. 
De particular importancia para la posición que estoy delineando es el intercambio que ocurre al momento de establecer postulados. Los arqueólogos americanos apenas han comenzado a aceptar la visión constructivista del conocimiento, que implica que la información no es neutra (Wylie, 1989a, 1992b). No estamos acostumbrados a la idea de negociar los valores de la verdad con el público no arqueológico que son afectados por nuestro trabajo. Sin embargo, tal negociación no degrada la arqueología, aunque los arqueólogos pueden, de vez en cuando, ser presionados por los miembros de las comunidades en las que trabajan. El resultado eventual será una arqueología mucho más rica. No producirá una única interpretación de los datos, sino muchas interpretaciones; no una literatura uniformemente útil, sino muchas literaturas inconmensurables. De esta forma, la información arqueológica puede tener valor, no solo para los profesionales sino para las personas cuya identidad y posiciones de clase son afectadas por lo que los arqueólogos hacen y piensan sobre el pasado.

Este es un punto incómodo, pero bueno para permanecer. Hay que negociar constantemente el valor de la investigación y formar alianzas continuamente, mientras que al mismo tiempo se restablece la propia independencia intelectual e institucional. Es probable que este proceso produzca una mejor comprensión de algunos restos del pasado; ciertamente producirá comprensiones del pasado que satisfagan a los que constituyen la arqueología. Estas comunidades incluyen no solamente arqueólogos y antropólogos sino también personas cuyas identidades son afectadas por lo que es dicho acerca de sus pasados. Los resultados pueden incluir cierta comprensión de nuestra sociedad como una sociedad orientada al lucro, basada en clases y que habitualmente utiliza muchos medios de marginación para lograr sus fines. Ciertamente, ilustra hasta qué punto Edmund Morgan tenía razón cuando dijo que la pobreza es esencial a la democracia Americana. Si nuestra sociedad está basada en una jerarquía que requiere la esclavitud o la pobreza de algunos, entonces ¿cómo y a través de qué medios se reproduce esta jerarquía? Una arqueología histórica del capitalismo puede ofrecer este conocimiento a aquellos que quieren saber cómo nosotros y ellos llegamos a estar donde estamos ahora. Pero también se pueden formar alianzas con esas mismas personas, para desafiar la opresión que yace desigualmente sobre todos nosotros y generar reformas.

\section{AGRADECIMIENTOS}

Este artículo fue presentado en la División Arqueológica en la $92^{\circ}$ Reunión anual de la AAA como una conferencia titulada "Visión y paisaje humano: Acercamientos a sitio y vista". Paul Mullins, Thomas Patterson y Robert Paynter han leído el ensayo varias veces y han hecho comentarios escritos detallados en varios borradores. Cada uno ha ayudado a hacer este ensayo más coherente, enfocado y definido. Jean-Paul Dumont dirigió mis esfuerzos al enmarcar lo material en la antropología cultural y los estudios culturales; Joanne Rappaport con materiales sobre historia local entre comunidades. Michael Lucas realizó varias sugerencias útiles sobre este artículo.

Sydney Mintz y Robert Preucel, dos revisores de la American Anthropologist, realizaron sugerencias centrales en la reorganización del material usado aquí. Hannah Jopling brindó amablemente material sobre historias orales. Henry Miller y Silas Hurry me ayudaron a pensar a la conexión entre la ciudad de St. Mary y Annapolis usando el urbanismo barroco, y entre Annapolis y Baltimore usando el urbanismo panóptico. Varios estudiantes de mi departamento me ayudaron con los varios borradores de este artículo. Mi agradecimiento va particularmente a Andrew Tobiason. 
La arqueología reportada en Annapolis ha sido patrocinada conjunta y generosamente por la Fundación histórica de Annapolis y la Universidad de Maryland. Agradezco a mi esposa, Nan S. Wells por su continuo apoyo. Asumo la responsabilidad por los errores en el ensayo.

\section{REFERENCIAS BIBLIOGRÁFICAS}

Althusser, L. (1971). Ideology and Ideological State Apparatuses. In Brewster, B. (Ed.). Lenin and Philosophy (p. 127-186). New York: Monthly Review Press.

Anderson, M. (1991). Selling the Past History in Museums in the 1990s. Australian Historical Studies, 24(96). p. $130-141$.

Bacon, E. N. (1968). Design of Cities. New York: Viking Press.

Barnett, S., \& Silverman, M. (1979). Separations in Capitalist Societies: Persons, Things, Units and Relations. In Barnett, S. \& Silverman, M. (Eds.). Ideology and Everyday Life (p. 41-81). Ann Arbor: University of Michigan Press.

Barrett, J. C. (1988). Fields of Discourse: Reconstituting a Social Archaeology. Critique of Anthropology, 7. p. 5-16.

Bodor, T. W., Anroman, G. M., Russo, J. B., Jopling, H., \& Etherton, K. M. (1993). Culture Resource Survey at the United States Naval Academy in Annapolis, Maryland. Report Prepared for Chesapeake Division Naval Facilities Engineering Command, United States Naval Academy. Archaeology in Annapolis Project Annapolis: Historic Annapolis Foundation.

Bower, B, J. C., \& Rushing, B. (1984). Report on the Archaeological Testing Program in the African Meeting House Basement. Boston: Massachusetts Historical Commission.

Bruner, E. (1994). Abraham Lincoln as Authentic Reproduction: A Critique of Postmodernism. American Anthropologist, 96(2). p. 397-415.

Carr, L. G., \& Jordan, D. (1974). Maryland's Revolution of Government, 1689-1692. Ithaca: Cornell University Press.

Carr, L. G., Morgan, P. \& Russo, J. (eds.) (1988). Colonial Chesapeake Society. Chapel Hill: University of North Carolina Press for the Institute of Early American History and Culture.

Carr, L. G., \& Walsh, L. S. (1980). Inventories and the Analysis of Wealth Consumption Patterns in St. Mary's County, Maryland, 1658-1777. Historical Methods, 13(2). p. 81-104.

Carr, L. G., \& Walsh, L. S. (1988). Economic Diversification and Labor Organization in the Chesapeake, 1650-1820. In Innes, S. (Ed.). Work and Labor in Early America (p. 144-188). Chapel Hill: University of North Carolina Press for the Institute of Early American History and Culture.

Carson, C., Hoffman, R., \& Albert, P. (eds.) (1993). Of Consuming Interests: The Style of Life in the Eighteenth Century. Charlottesville: University of Virginia Press.

Clifford, J. (1988). The Predicament of Culture. Cambridge: Harvard University Press.

Clifford, J., \& Marcus, G. (eds) (1986). Writing Culture. Berkeley: University of California Press.

Connerton, P. (1989). How Societies Remember. Cambridge: Cambridge University Press.

Cotter, J. (1958). Archaeological Excavations at Jamestown, Virginia. Washington, DC, U.S. National Park Service Archaeological Research Series, No. 4.

Cotter, J., \& Hudson, P. (1957). New Discoveries at Jamestown. Washington: Government Printing Office. 
Cotter, J., Moss, R., Gill, B. \& Kim, J. (1988). The Walnut Street Prison Workshop. Philadelphia: The Athenaeum of Philadelphia.

Cox, C. J., \& Seidel, J. L. (1994). Guide for Cultural Resource Management, United States Naval Academy. Legacy Resource Management Program Archaeological Reconnaissance Survey. Prepared by Archaeology in Annapolis. Annapolis: Historic Annapolis Foundation.

Cox, C. J., Seidel, J. L., Jopling, H., Russo, J. B., Jones, L. \& O'Reilly, C. (1994). Map Analysis, Oral Histories and Tract Histories. Legacy Resource Management Program Archaeological Reconnaissance Survey. Prepared by Archaeology in Annapolis. Annapolis: Historic Annapolis Foundation.

Deming, G. (1988). History's Anthropology: The Death of William Gooch. Lanham: University Press of America.

Derrida, J. (1978). Writing and Difference. London: Routledge \& Keegan Paul.

Dorst, J. (1989). The Written Suburb: An American Site, An Ethnographic Dilemma. Philadelphia: University of Pennsylvania Press.

During, S. (1993). The Cultural Studies Reader. London: Routledge.

Eco, U. (1986) [1967]. Travels in Hyperreality: Essays. New York: Harcourt Brace Jovanovich, Inc.

Eppersen, T. (1990a). "To Fix a Perpetual Brand": The Social Construction of Race in Virginia, 1675-1750. Ann Arbor: University Micro-films.

Eppersen, T. (1990b) Race and the Disciplines of the Plantation. Historical Archaeology, 24(4). p. 29-36.

Ferguson, L. (1992). Uncommon Ground: Archaeology and Early African America, 1650-1800. Washington: Smithsonian Institution Press.

Fields, B. J. (1985). Slavery and Freedom on the Middle Ground: Maryland During the Nineteenth Century. New Haven: Yale University Press.

Foley, D. (1990). Learning from Capitalist Culture. Philadelphia: University of Pennsylvania Press.

Foucault, M. (1979). Discipline and Punish: The Birth of the Prison. New York: Random House.

Friedman, J. (1992). The Past in the Future: History and the Politics of Identity. American Anthropologist, 95(4). p. 837-859.

Gable, E., \& Handler, R. (1994). The Authenticity of Documents at Some American History Museums. The Journal of American History, 81(1). p. 119-136.

Gathercole, P., \& Lowenthal, D. (eds) (1990). The Politics of the Past. London: Unwin Hyman.

Genovese, E. (1974). Roll, Jordan, Roll: The World the Slaves Made. New York: Pantheon.

Gero, J. M., Lacy, D. M., \& Blakey, M. L. (1983). The Socio-Politics of Archaeology. Amherst: Research Report Number 23, Department of Anthropology, University of Massachusetts.

Gero, J. M., \& Conkey, M. C. (1991). Engendering the Past. Oxford: Basil Blackwell.

Giddens, A. (1984). The Constitution of Society: Outline of the Theory of Structuralism. Cambridge: Polity Press.

Goodwin, C., Saunders, S., Moran, M., \& Landon, D. (1993). Phase II/III Archaeological Investigations of the Gott's Court Parking Facility, Annapolis, Maryland. Report prepared for the City of Annapolis. Frederick: R. Christopher Goodwin and Associates, Inc.

Grossberg, L., Nelson, C., \& Treichler, P. A. (eds) (1992). Cultural Studies. London: Routledge.

Habermas, J. (1970). Toward a Theory of Communicative Competence. Inquiry, 13(4). p. 360-376.

Habermas, J. (1979). Communication and the Evolution of Society. Boston: Beacon Press. 
Habermas, J. (1984). The Theory of Communicative Action. Vol. 1, Reason and the Rationalization of Society. Boston: Beacon Press.

Handler, R. (1988). Nationalism and the Politics of Culture In Quebec. Madison: University of Wisconsin Press.

Handsman, R. (1980). The Domains of Kinship and Settlement in Historic Goshen: Signs of a Past Cultural Order. Artifacts, 9. p. 2-7.

Handsman, R. (1981). Early Capitalism and the Center Village of Canaan, Connecticut: A Study of Transformations and Separations. Artifacts, 9(3). p. 1-21.

Hodder, I. (1982). Symbols in Action. Cambridge: Cambridge University Press.

Hodder, I. (1986). Politics and Ideology in the World Archaeological Congress 1986. Archaeological Review from Cambridge, 5. p. 113-118.

Hymes, D. (ed) (1972). Reinventing Anthropology. New York: Pantheon.

Isaac, R. (1982). The Transformation of Virginia1740-1790. Chapel Hill: University of North Carolina Press.

Ives, S. M. (1979). The Formation of a Black Community in Annapolis, 1870-1885. In Mitchell, R. \& Mueller, E. (Eds.). Geographical Perspectives on Maryland's Past (p. 129-149). College Park, : University of Maryland.

Johnson, M. (1993). Housing Culture. London: University College London Press.

Jopling, H. (s.d.) Oral History Interview with Former Residents of Gott's Court, Annapolis, Maryland. Manuscript in possession of author.

Kemp, R. (1988). Planning, Public Hearings, and the Politics of Discourse. In Forester, J. (Ed.). Critical Theory and Public Life (p. 177-201). Cambridge: MIT Press.

Layton, R. (Ed.) (1988). Who Needs the Past? Indigenous Values and Archaeology. London: Unwin Hyman.

Layton, R. (1989). Conflict in the Archaeology of Living Traditions. London: Unwin Hyman.

Leone, M. P. (1978). Time in American Archaeology. In Redman, C. (Ed.). Social Archaeology Beyond Subsistence and Dating (p. 25-36). New York: Academic Press.

Leone, M. P. (1981a). Archaeology's Relationship to the Present and the Past. In Gould, R. \& Schiffer, M. (Eds.). Modern Material Culture (p. 5-13). New York: Academic Press.

Leone, M. P. (1981b). The Relationship Between Artifacts and the Public in Outdoor History Museums. In Cantwell, A., Bennett Griffin, J. \& Rothschild, N. A. (Eds.). The Research Potential of Anthropological Museum Collections (p. 301-313). New York: New York Academy of Sciences.

Leone, M. P. (1983). Method as Message. Museum News, 62(1). p. 35-41.

Leone, M. P. (1984). Interpreting Ideology in Historical Archaeology: Using the Rules of Perspective in the William Paca Gardening Annapolis, Maryland. In Miller, D. \& Tilley, C. (Eds.). Ideology, Power and Prehistory, (p. 25-36). Cambridge: Cambridge University Press.

Leone, M. P. (1987). Rule by Ostentation: The Relationship Between Space and Sight in Eighteenth Century Landscape Architecture in the Chesapeake Region of Maryland. In Kent, S. (Ed.). Method and Theory for Activity Area Research. (p. 605-632). New York: Columbia University Press.

Leone, M. P., \& Little, B. J. (1993). Artifacts as Expressions of Society and Culture: Subversive Genealogy and the Value of History. In Lubar, S \& Kingery, W. D. (Eds.). History from Things (p. 160-181). Washington DC: Smithsonian Institution Press.

Leone, M. P., Potter, P. B. \& Shackel, P. A. (1987). Toward a Critical Archaeology. Current Anthropology, 28(3). p. 283-302. 
Leone, M. P. \& Shackel, P. (1987). Forks, Clocks, and Power. In Ingersoll, D. \& Bronitski, G. (Eds.). Mirror and Metaphor, Material Culture and Social Construction of Reality (p. 45-61). Lanham: University Press of America.

Leone, M. P., \& Shackel, P. (1990) Plane and Solid Geometry in Colonial Gardens in Annapolis, Maryland. In Kelso, W. \& Most, R. (Eds). Earth Patterns: Essays in Landscape Architecture (p. 153-167). Charlottesville: University of Virginia Press.

Little, B. J. (1994). Considering the Hermaphroditic Mind: Comments on "The Interplay of Evidential Constraints and Political Interest: Recent Archaeological Work on Gender. American Antiquity, 59(3). p. 539-544.

Logan, G. C. (1991). Archaeology at Charles Carrolls's House and Garden and of His African American Slaves. Annapolis: Historic Annapolis Foundation Brochure.

Lowenthal, D. (1985). The Past Is a Foreign Country. Cambridge: Cambridge University Press.

Lukács, G. (1971). Reification and the Consciousness of the Proletariat. In Livingstone, R., History and Class Consciousness (p. 83-222). Cambridge: MIT Press.

MacCannell, D. (1976). The Tourist. New York: Schocken.

Marcus, G. (1989). Imagining the Whole: Ethnography's Contemporary Efforts to Situate Itself. Critique of Anthropology, 9(3). p. 7-30.

Marcus, G., \& Fischer, M. (eds.) (1986). Anthropology as Cultural Critique. Chicago: University of Chicago Press.

McGuire, R. H. (1989). The Sanctity of the Grave: White Concepts and American Indian Burials. In Layton, R. (Ed.). Conflict in the Archaeology of Living Traditions (p. 167-184). London: Unwin Hyman.

McGuire, R. H. (1992). A Marxist Archaeology. Orlando: Academic Press.

Mcintosh, R. J., Mcintosh, S. K., \& Togola, T. (1989). People Without History. Archaeology, (JanuaryFebruary). p. 74-107.

McMullen A., \& Handsmane, R. (eds) (1987). A Key into the Language of Wood splint Baskets. Washington: American Indian Archaeological Institute.

Messick, B. (1993). The Calligraphic State: Textual Domination and History in a Muslim Society. Berkeley and Los Angeles: University of California Press.

Miller, H. (1986). Discovering Maryland's First City: A Summary Report on the 1981-1984 Archaeological Excavations in St. Mary's City, Maryland Archaeology Series, No.2. St. Mary's City, MD: St Mary's City Commission.

Miller, H. (1988). Baroque Cities in the Wilderness Archaeology and Urban Development in the Colonial Chesapeake. Historical Archaeology, 22(2). p. 57-73.

Moffett, M. (1989). Coming of Age in New Jersey: College and American Culture. New Brunswick: Rutgers University Press.

Morgan, E. S. (1975). American Slavery, American Freedom. New York: W. W. Norton \& Company.

Mullins, P., \& Warner, M. (1993). Final Archaeological Investigations at the Maynard-Burgess House (18AP64): An African-American Household in Annapolis, Maryland. Report prepared for Archaeology in Annapolis. Annapolis: Historic Annapolis Foundation.

Newman, K. S. (1988). Falling from Grace: The Experience of Downward Mobility in the American Middle Class. New York: The Free Press.

Noel, H. I. (1963). Here Lies Virginia. New York: Alfred A. Knopf. 
Noel, H. I. (1983). Martin's Hundred. New York: Alfred A. Knopf.

Orser, C. E. Jr. (1988). The Material Basis of the Postbellum Tenant Plantation: Historical Archaeology in the South Carolina Piedmont. Athens: University of Georgia Press.

Passerini, L. (1987). Fascism in Popular Memory: The Cultural Experience of the Turin Working Class. Cambridge: Cambridge University Press.

Patterson, T. (1986). The Last Sixty Years: Toward a Social History of Americanist Archaeology in the United States. American Anthropologist, 88(1). p. 7-26.

Paynter, R. (1983). Field or Factory? Concerning the Degradation of Archaeological Labor. In Gero, J. et al., (Eds.) The Socio-Politics of Archaeology (p.17-29). Amherst: Research Report. No. 23, Department of Anthropology University of Massachusetts.

Potter, P. B. Jr. (1994). Public Archaeology in Annapolis: A Critical Approach to History in Maryland's "Ancient" City. Washington: Smithsonian institution press.

Potter, P. B. Jr., \& Leone, M. P. (1992). Establishing the Roots of Historical Consciousness in Modern Annapolis, Maryland. In Christine, I. K., Kreames, M. \& Lavine, S. D. (Eds.). Museums and Communities: The Politics of Public Culture. (p. 476-505). Washington DC: Smithsonian Institution Press.

Rappaport, J. (1988). History and Everyday Life in the Colombian Andes. Man, 23(4). p. 718-736.

Rappaport, J. (1990). The Politics of Memory: Native Historical Interpretation in the Colombian Andes. Cambridge: Cambridge University Press.

Rappaport, J. (1994). Cumbe Reborn: An Andean Ethnography of History. Chicago: University of Chicago Press.

Rowe, J. (1966). The Renaissance Foundations of Anthropology. American Anthropologist, 67(1). p. 1-20.

Russo, J. (s. d.) The Structure of the Anne Arundel County Economy. In Walsh, L. S. (ed.). Annapolis and Anne Arundel County, Maryland: A Study of Urban Development in a Tobacco Economy: 1649-1776. Manuscript on file, Historic Annapolis Foundation, Annapolis.

Schuyler, R. L. (1978[1970]) Historical and Historic Sites Archaeology as Anthropology: Basic Definitions and Relationships. In Schuyler, R. L (Ed.). Historical Archaeology: A Guide to Substantive and Theoretical Contributions (p. 27-31). Farmingdale: Bay Wood Publishing Co.

Shackel, P. A. (1991). Consumerism and the Structuring of Social Relations: A Historical Archaeological Perspective. In Brown, R., \& Brown, P. (Eds.). Digging into Popular Culture: Theories and Methodologies in Archaeology, Anthropology and Other Fields, (p. 36-47). Bowling Green: Bowling Green State University Press.

Shackel, P. A. (1993). Personal Discipline and Material Culture: An Archaeology of Annapolis, Maryland 1695-1870. Knoxville: University of Tennessee Press.

Shanks, M., \& Tilley, C. (1987a). Reconstructing Archaeology. Cambridge: Cambridge University Press.

Shanks, M., \& Tilley, C. (1987b). Social Theory and Archaeology. Albuquerque: Albuquerque University of New Mexico Press.

Shennan, S. (Ed.) (1989). Archaeological Approaches to Cultural Identity. London: Unwin Hyman.

Smith, B. C. (1985). After the Revolution, the Smithsonian History of Everyday Life in the Eighteenth Century. New York: Pantheon books.

Smithsonian Institution (1985). Opening oral text for After the Revolution, permanent exhibition of National Museumof American History. Washington, DC: Smithsonian Institution.

South, S. (1977). Research Strategies in Historical Archaeology: The Scientific Paradigm. In South, S. (Ed.). Research Strategies in Historical Archaeology (p. 1-12). New York: Academic Press. 
Spector, J. D. (1993) What This Awl Means: Feminist Archaeology at a Wahpeton Dakota Village. St. Paul: Minnesota Historical Society Press.

Stone, G. (1974). St. John's: Archeological Questions and Answers. Maryland Historical Magazine, 69(2). p. 146-168.

Tate, T., \& Ammerman, D. (Eds.) (1979). The Chesapeake in the Seventeenth Century: Essays on Anglo-American Society and Politics. Chapel Hill: University of North Carolina Press for the Institute of Early American History and Culture.

Varenne, H., Hill, C. \& Byers, P. (1992). Ambiguous Harmony: Family Talk in America. Norwood: Ablex Publishing Corp.

Wallace, M. (1981). Visiting the Past History Museums in the United States. Radical History Review, 25. p. 6396.

Wallace, M. (1984). Mickey Mouse History. Radical History Review, 32(March). p. 33-57.

Walsh, L. S. (Ed.) (1983). Annapolis and Anne Arundel County Maryland: A Study of Urban Development in a Tobacco Economy: 1649-1776. Manuscript on file, Historical Annapolis Foundation, Annapolis.

Warner, M. S. (1992). Test Excavations at Gott's Court, Annapolis, Maryland 18AP52. On file at Historic Annapolis Foundation.

Warner, M. S., \& Mullins, P. R. (1993). Phase I, II Archaeological Investigations at the Court-house Site 18AP63, An 1870-1970 African American Neighborhood in Annapolis, Maryland. Report prepared by Archaeology in Annapolis. Annapolis: Historic Annapolis Foundation.

Williams, B. (1988). Upscaling Downtown. Ithaca: Cornell University Press.

Wylie, A. (1985). Putting Shakertown Back Together: Critical Theory in Archaeology. Journal of Anthropological Archaeology, 4(2). p. 133-147.

Wyilie, A. (1989a). Archaeological Cables and Tacking: The Implications of Practice for Bernstein's "Options Beyond Objectivism and Relativism." Philosophy of Social Sciences, 19. p. 1-18.

Wylie, A. (1989b) Matters of Face and Matters of Interest. In Shannen, S. (Ed.). Archaeological Approaches to Cultural Identity (p. 94-109). London: Unwin Hyman.

Wylie, A. (1990). Feminist Critiques and Archaeological Challenges. In Walde, D. \& Willows, N. (Eds.). The Archaeology of Gender (p. 17-23). Calgary: University of Calgary Archaeological Association.

Wylie, A. (1991). Gender Theory and the Archaeological Record: Why Is There No Archaeology of Gender? In Gero, J. \& Conkey, M. (Eds.). Engendering Archaeology: Women and Prehistory (p. 31-54). Oxford: Basil Blackwell.

Wylie, A. (1992a). The Interplay of Evidential Constraints and Political Interests: Recent Archaeological Research on Gender. American Antiquity, 57(1). p. 15-35.

Wylie, A. (1992b). On "Heavily Decomposing Red Herrings": Scientific Method in Archaeology and the Ladening of Evidence with Theory. In Embree, L. (Ed.). Meta archaeology: Reflections by Archaeologists and Philosophers (p. 269-288). Dordrecht: Kluwer Academic Publishers. 